\title{
Recent Advances in 3D Assessment of Various Fetal Anomalies
}

\section{${ }^{1}$ Ritsuko K Pooh, ${ }^{2}$ Asim Kurjak}

${ }^{1}$ CRIFM Clinical Research Institute of Fetal Medicine PMC, Osaka, Japan

${ }^{2}$ Department of Obstetrics and Gynecology, Medical School, University of Zagreb, Sveti Duh Hospital, Zagreb, Croatia

Correspondence: Ritsuko K Pooh, CRIFM Clinical Research Institute of Fetal Medicine PMC, 3-7, Uehommachi 7, Tennoji Osaka \#543-0001, Japan, Phone: +81-6-6775-8111, Fax: +81-6-6775-8122, e-mail: rkpooh@me.com

\begin{abstract}
Recent advances of ultrasound technology including 3D/4D sonography have revealed embryonal/fetal morphology, intrauterine vascularity and fetal behavior from early gestation. Modern 'sonoembryology' allows the definition of in vivo anatomy including visualization of dynamic features, which cannot be characterized in fixed specimens after embryonic death in embryology. Furthermore, recent highresolutional ultrasound technologies have remarkably approached accurate prenatal diagnoses with vivid and distinct sonographic depiction. Nowadays, the antenatal diagnosis is no longer 'maybe' nor ambiguous, owing to progressive 3D/4D ultrasound which have contributed to the field of embryology, fetal physiology and pathology.
\end{abstract}

Keywords: Three-dimensional ultrasound, fetus, anomaly.

\section{INTRODUCTION}

Definition of the normal anatomy of the human embryo is essential to assess embryonic development and growth as well as to identify and diagnose congenital anomalies in early pregnancy. A major limitation to define, noninvasively, human embryonic anatomy has been the resolution of the tools available. The term 'sonoembryology' was first coined in, $1990^{1}$ after the introduction of high-frequency transvaginal transducers. Three-dimensional (3D) sonography performed with a transvaginal approach has expanded the depth of inquiry and allowed three-dimensional sonoembryology. ${ }^{2}$ Owing to recent advances of 3D ultrasound technology, ultrasound detection of surface anatomy, organ orientation has rapidly improved its resolution and image quality.

\section{RECENT ADVANCES OF 3D ULTRASONOGRAPHY}

Recent advances of 3D/4D sonography have assessed not only structural but also functional early human development. ${ }^{3}$

3D images of embryos were generated using the highfrequency transvaginal transducer (Voluson ${ }^{\circledR}$ E8 with 12 $\mathrm{MHz} / 256$ element transvaginal transducer, GE Health care, Milwaukee, USA). Demonstration of an embryo of less than

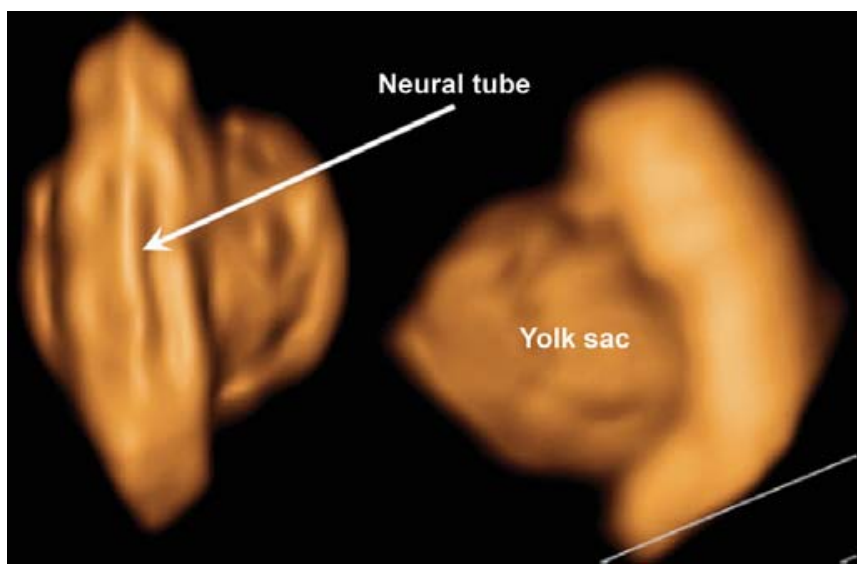

Fig. 1: Neural tube of 6-week-embryo. The neural tube of an embryo with CRL of $5.5 \mathrm{~mm}$ is clearly visualized by $3 \mathrm{D}$ ultrasound

$10 \mathrm{~mm}$ (greatest length) has been difficult in the past and not visualized in detail. Figure 1 illustrates a $5.5 \mathrm{~mm}$ longembryo with its yolk sac at six weeks of gestation, with demonstration of the neural tube. During the early embryonic period, the central nervous system anatomy rapidly changes in appearance. 3D sonography using transvaginal sonography with high-resolution probes allows imaging of early structures in the embryonic brain. This can be accomplished through the use of three orthogonal planes, and "tomographic ultrasound imaging". Serial examinations allow obtaining similar sections of the fetal brain at different stages of development. Therefore, it is possible to document 


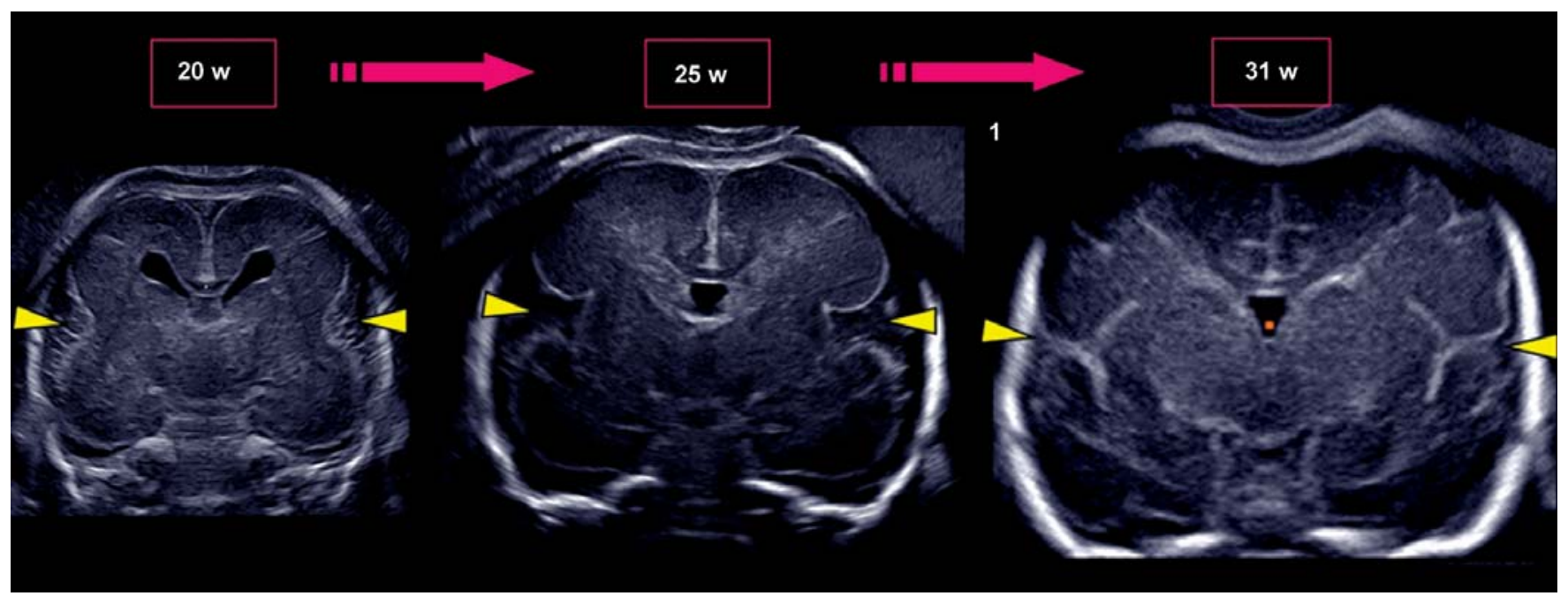

Fig. 2: Changing appearance of Sylvian fissure in the anterior coronal section by transvaginal 3D sonography. At 20 weeks of gestation, bilateral Sylvian fissures (arrow heads) appear to be indentations (left). With cortical development, Sylvian fissures are formed during the latter half of second trimester (middle) and become as lateral sulci (right). Sylvian fissure appearance is one of the most reliable ultrasound markers for the assessment of cortical development

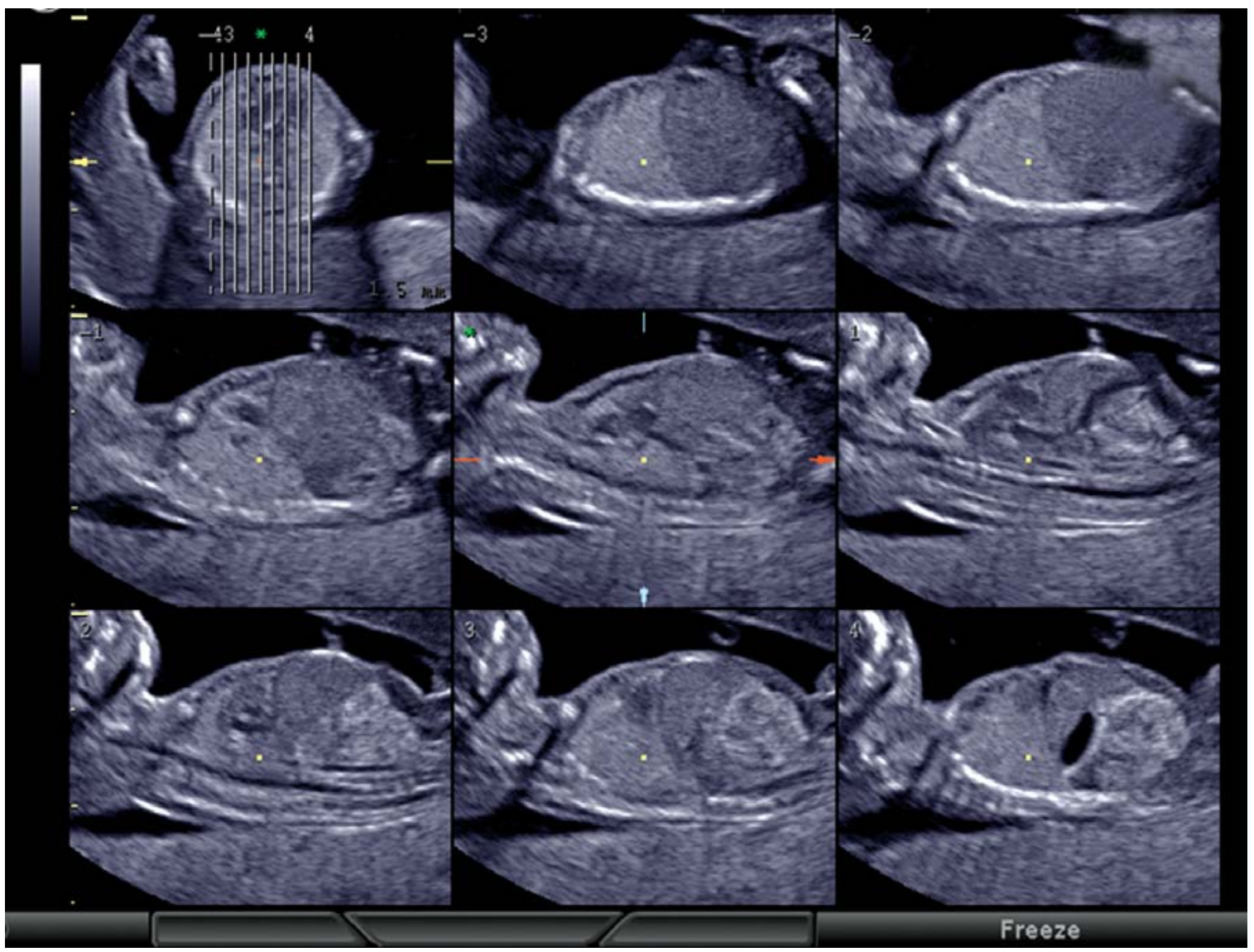

Fig. 3: Tomographic ultrasound sagittal image of thoracoabdominal structure at $\mathbf{1 3}$ weeks. Note clear visualization of the lung-liver border (diaphragmatic line), lung, liver, stomach, bowels, umbilical vein and ductus venosus

the changes in CNS development from early embryonic period. Figure 2 shows dramatical changes of Sylvian fissures between 20 and 31 weeks demonstrating by transvaginal 3D ultrasound. Observation of the brain cortical development should have a great potential to discover migration disorders during pregnancy. Thoraco-abdominal structures can also be imaged in the first trimester. For example, Figure 3 shows tomographic ultrasound imaging 


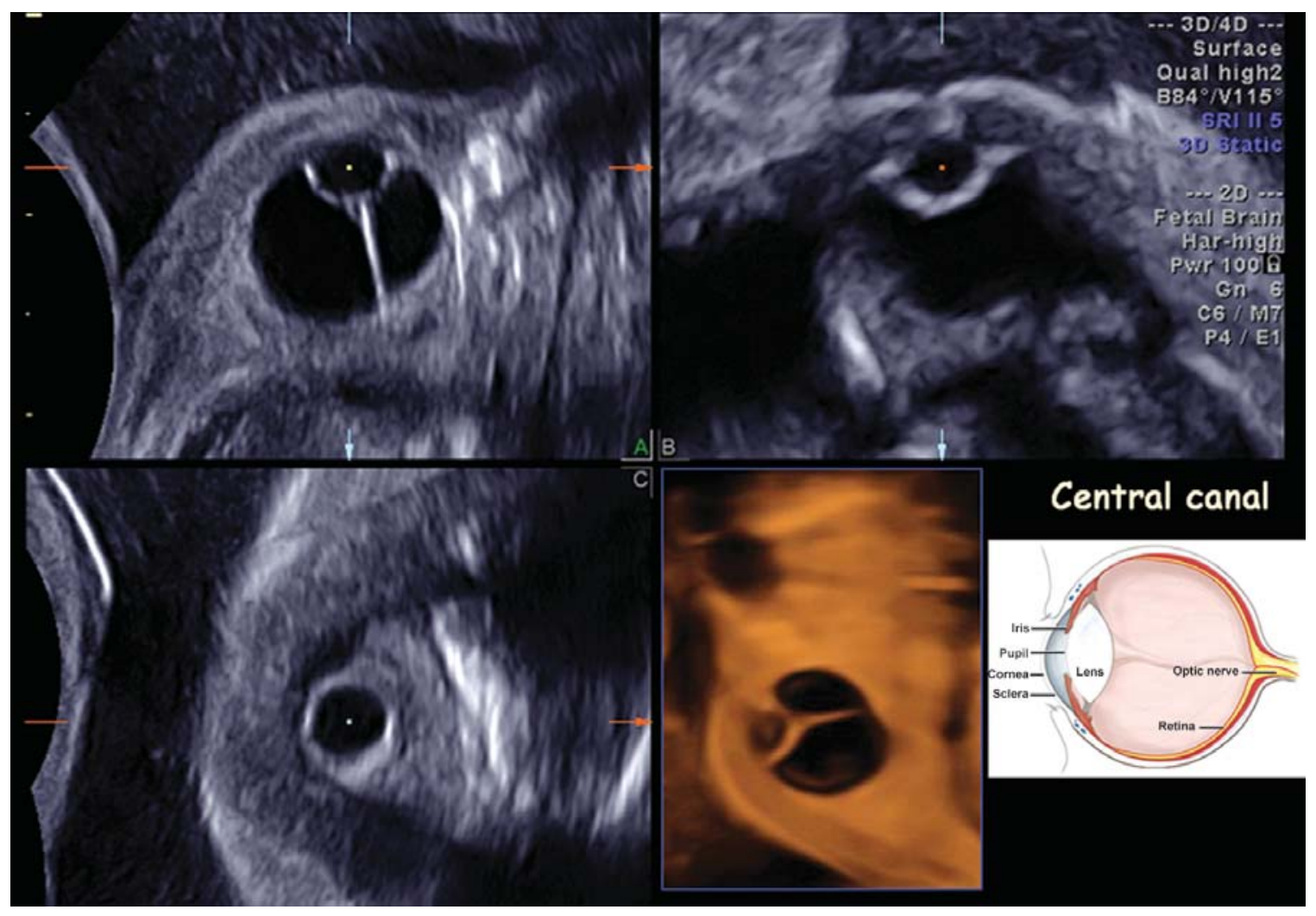

Fig. 4: Eyeball structure at 20 weeks. Three orthogonal view and reconstruction image of the eyeball. Lens and central canal towards the optic nerve is clearly demonstrated

of fetal chest and abdomen at 13 weeks of gestation. Clear visualization of the lung-liver interface can be of value in the early diagnosis of thoraco-abdominal abnormalities, such as a diaphragmatic hernia. The detailed structure of small parts, for instance the lenses of eyeballs (Fig. 4) can be visualized by 3D orthogonal view. 3D ultrasound technology will contribute to demonstration of in utero pathological changes of congenital diseases arising in utero.

Color Doppler detection and assessment of brain vessels in the early fetus using a transvaginal approach was reported $^{4,5}$ in 1993 and 1994. Clear visualization by transvaginal power Doppler of the common carotid arteries, internal and external carotid arteries, middle cerebral arteries at 12 weeks of gestation was reported in $1996 .{ }^{6}$ By using 3D power Doppler technology, the vascular anatomy can now be imaged clearly by identification of the common carotid arteries, internal carotid arteries, circle of Willis and middle cerebral arteries. It is important to stress that such images can be obtained at 12 weeks of gestation. Transvaginal high-resolution power Doppler can demonstrate the fine vascular structure of medullary vessels inside the fetal brain (Fig. 5). The powerful technology of 3D ultrasound will promisingly uncover the veil of unknown etiology of congenital diseases in vivo.

\section{PRENATAL DIAGNOSIS OF ANATOMICAL CONGENITAL ANOMALIES}

The prenatal diagnosis of congenital anomalies with ultrasound is based upon identification of a substantial departure of normal anatomy. This has been possible in the second and third trimester of pregnancy, and this achievement has made the diagnosis of congenital anomalies one of the objectives of modern prenatal care.

\section{Facial Anomalies}

A facial anomaly can be associated with a central nervous system anomaly (e.g. holoprosencephaly, Figs 6 and 7), be an isolated finding, or part of a syndrome. Detection of the presence or abscence of a nasal bone has been found to be of value in the assessment of aneuploidy in the first trimester of pregnancy (risk assessment for trisomy 21) ${ }^{7-11}$ Cicero and her colleagues reported that the nasal bone was absent 

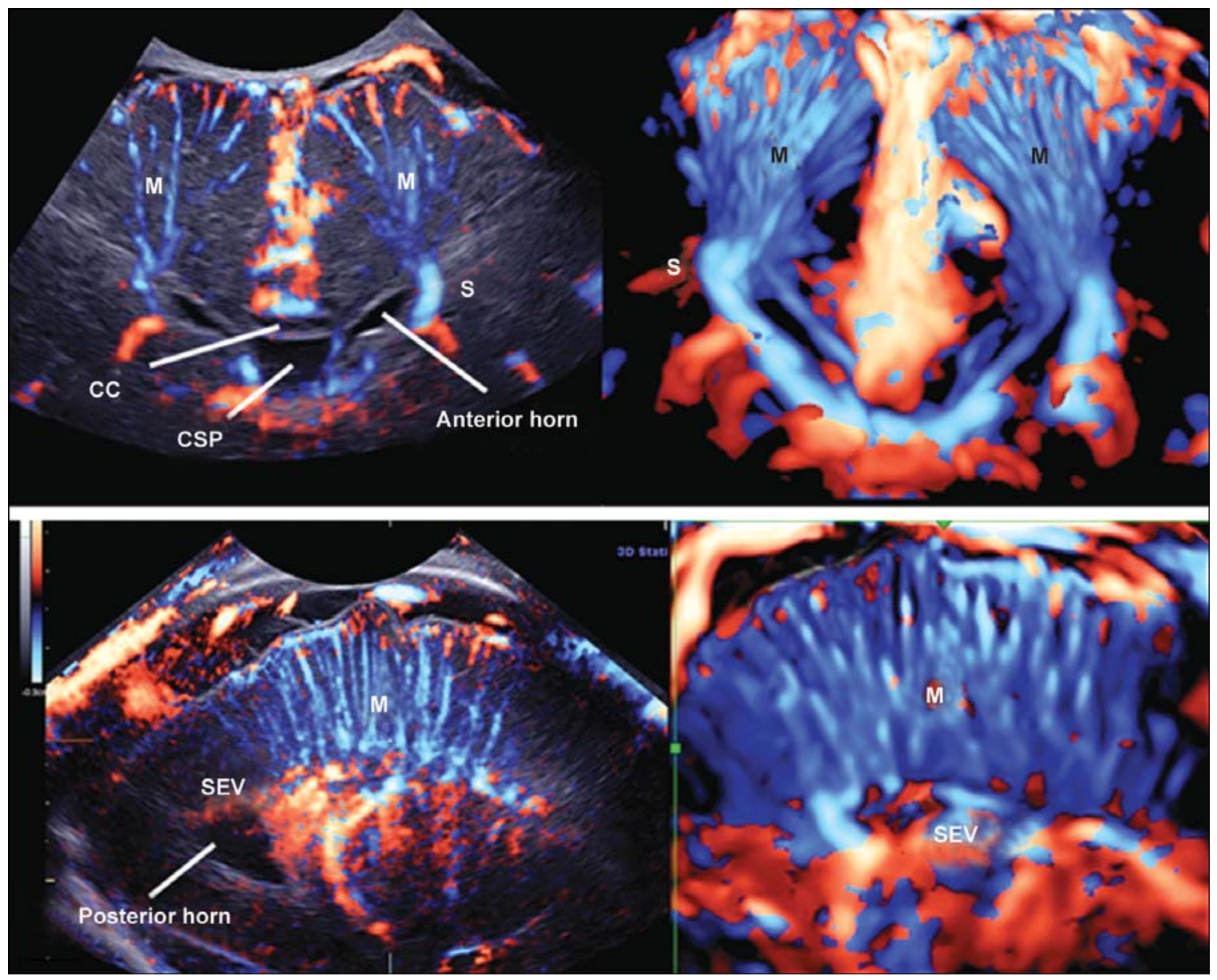

Fig. 5: Normal medullary vessels visualized by 3D power Doppler at 28 weeks. (upper left) Anterior coronal section of 2D bidirectional power Doppler image. Medullary vessels (M) and longitudinal caudate vein of Schlesinger (S) are well-demonstrated. CC; corpus callosum, CSP; cavum septum pellucidi, Ant. horn; anterior horn of the lateral ventricle. (upper right) Posteroanterior view of 3D reconstructed image of medullary vessels. Numerous medullary vessels (M) from pial mater towards Schlesinger veins (S) are demonstrated. (lower left) Parasagittal 2D bidirectional power Doppler image. Cerebral pial vessels are on the surface of cerebrum. Numerous linear vessels run down from the cerebral cortex towards subependymal veins (SEV) are medurally vessels (M). (lower right) Coronal view of 3D reconstructed image

in $113(0.6 \%)$ of the 20,165 chromosomally or phenotypically normal fetuses and in 87 (62.1\%) of the 140 fetuses with trisomy $21 .{ }^{11}$ 3D sonography allows obtaining a midsagittal section of the fetal face by utilizing the three orthogonal planes, and avoids the pitfall of obtaining a parasagittal view, which could lead to false negative results. Tomographic ultrasound imaging also allows demonstration of facial midline structures in detail, by examining close parallel sections. It is important to be aware that the quality of the orthogonal planes is dependent upon the original plane of acquisition. Rembouskos et $\mathrm{al}^{12}$ have expressed some reservations about the use of 3D for nasal bone assessment. Benoit and Chaoui ${ }^{13}$ described the diagnosis of bilateral or unilateral absence or hypoplasia of nasal bones in second trimester screening for Down syndrome by using 3D sonography with maximal mode rendering. Figure 8 shows craniofacial bony reconstructed image and the midsagittal section of fetal face of normal fetus and trisomy 21 fetuses in the first trimester. A short maxillary length has been associated with trisomy $21 .{ }^{14}$ Micrognathia (Fig. 9) can be detected as an isolated structural anomaly, as one of the features of a chromosomal abnormality, or a syndrome..$^{15}$ Figure 10 demonstrates the slow jaw development during pregnancy in a case of Pierre-Robin sequence, detected by serial 3D ultrasound scans. Assessment of the facial features, chin development and mandibular size by 3D ultrasound in the second and third trimesters has been reported. ${ }^{16}$ Facial abnormalities are often associated with craniosynostosis (Fig. 11) due to deformed cranial structure. Cleft lip and palate is one of common congenital facial anomalies. Cleft lip occurs unilaterally (Fig. 12) or bilaterally (Fig. 13). Recent 3D tomographic ultrasound can demonstrate anterior maxillary structure, indicating the 

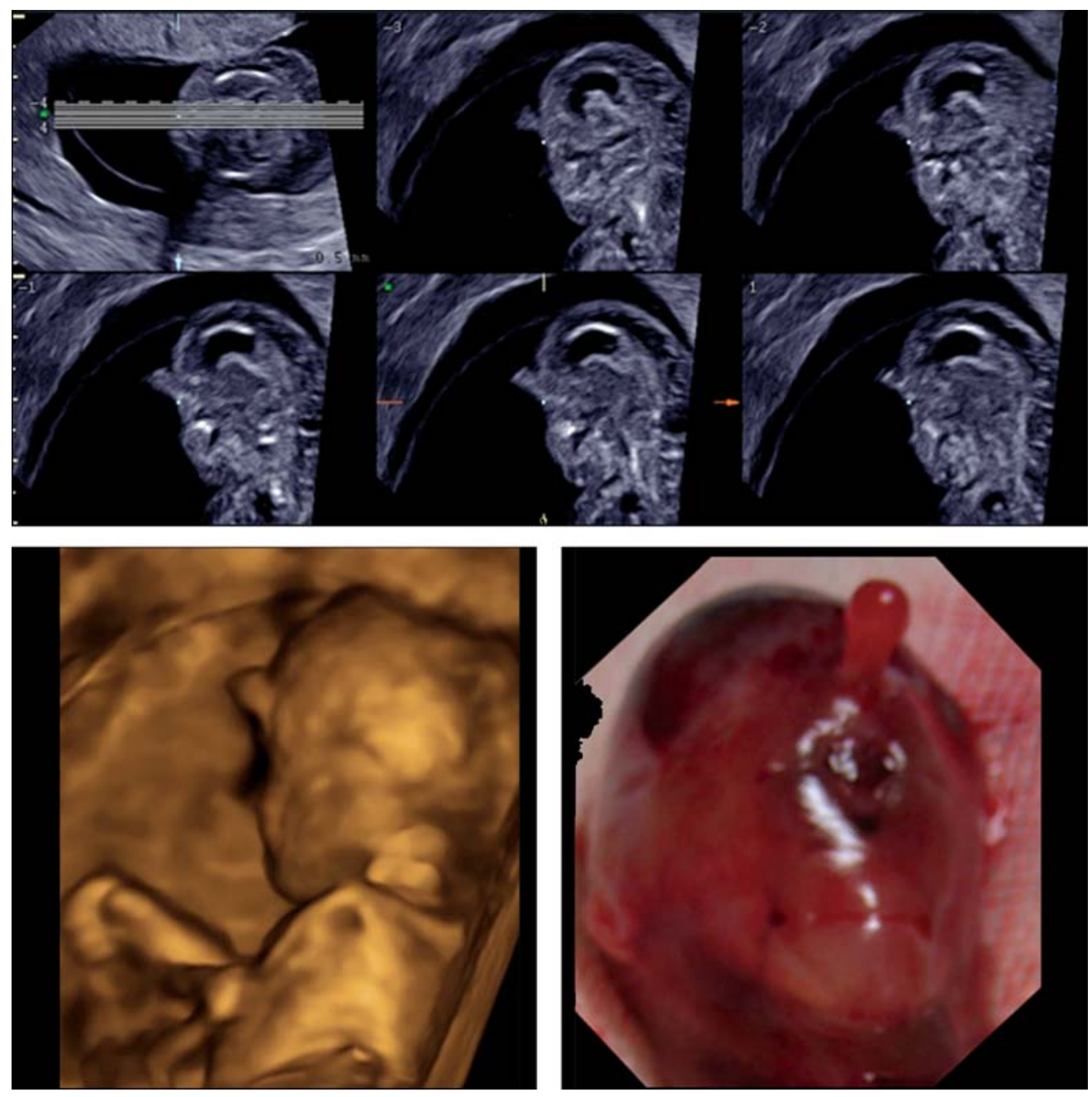

Fig. 6: Proboscis at 12 weeks (upper white and black figure) Tomographic ultrasound image of proboscis in a case of holoprosencephaly at 12 weeks. (lower left) 3D reconstructed image of the fetal face. (lower right) Facial appearance of aborted baby

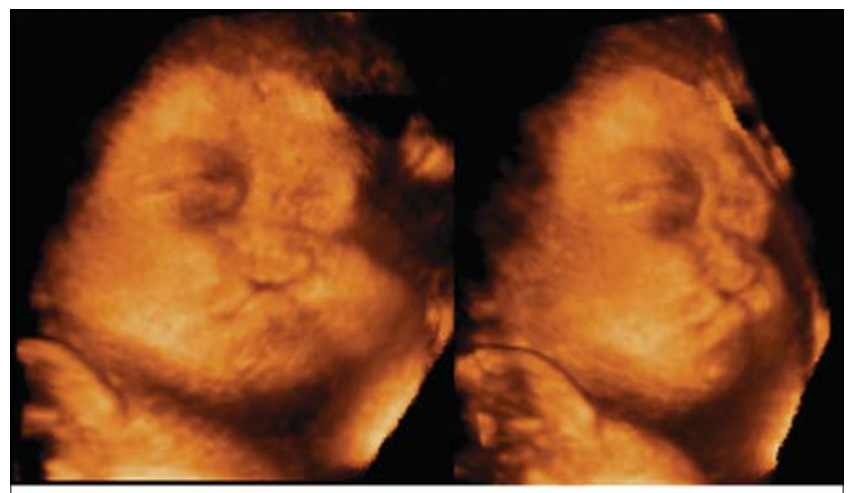

evidence of alveolar cleft presence shown on the Figure 12. Congenital cataract can also be visualized by 3D ultrasound as echogenic structure inside the lenses from as early as 14 weeks of gestation (Fig. 14).

\section{BRAIN ANOMALIES}

The brain structure should be understood as threedimensional structure. ${ }^{17,18}$ 3D sonographic assessment of premature brain in the early pregnancy was reported from 1995. ${ }^{19,20}$ From 2000, fetal brain assessment in the second

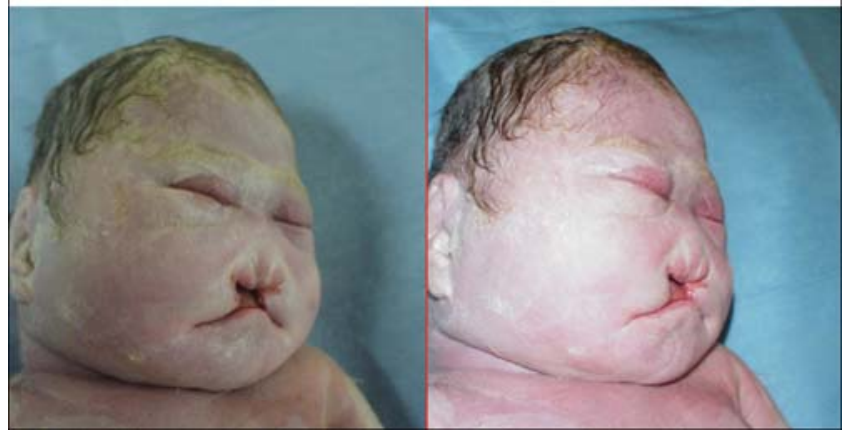
and third trimesters by 3D ultrasound was reported. ${ }^{17,18,21-30}$ Recent advanced 3D ultrasound has enabled to assess detailed brain structure as an understandable organ. 3D ultrasound abilities, such as tomographic ultrasound imaging and three orthogonal view,

Fig. 7: Arrhinia and exophthalmos at 28 weeks. (upper figures) Facial abnormality with arrhinia and exophthalmos is demonstrated in a case of holoprosencephaly, semilober type at 28 weeks. (lower pictures) Postmortem facial appearance of the same baby 


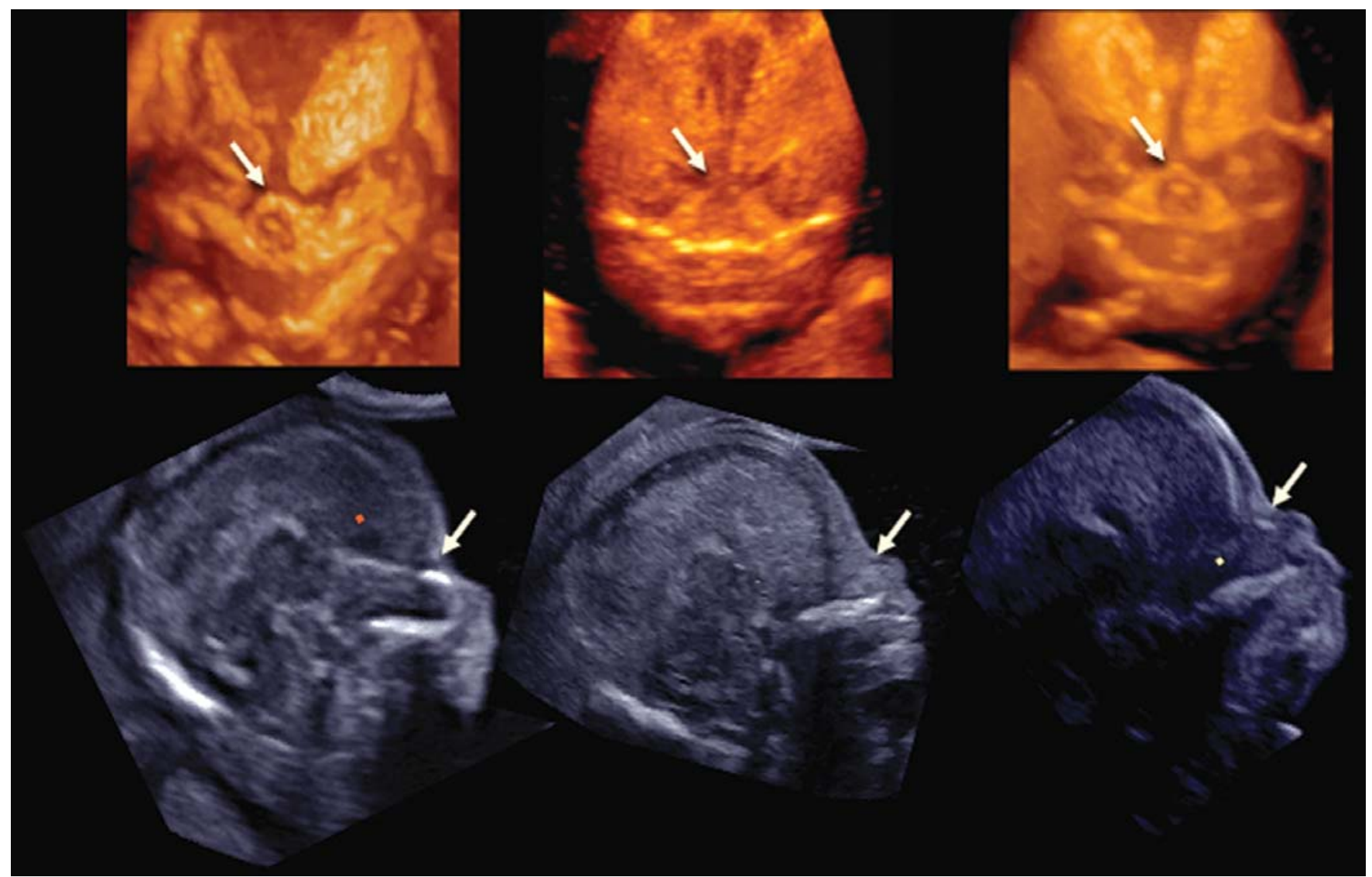

Fig. 8: Midsagittal 2D image of fetal profile and craniofacial bony reconstructed image of normal fetus (left) and trisomy 21 fetuses (middle and right) at 13-14 weeks of gestation. (left) Normal fetus. Nasal bone is clearly visualized in both 2D and 3D images (arrows). (middle) Nasal bone defect in a case of trisomy 21. Nasal bone is completely missing in both 2D and 3D. (right) Nasal bone hypoplasia in a case of trisomy 21 . Small nasal bone is visualized in both $2 \mathrm{D}$ and 3D

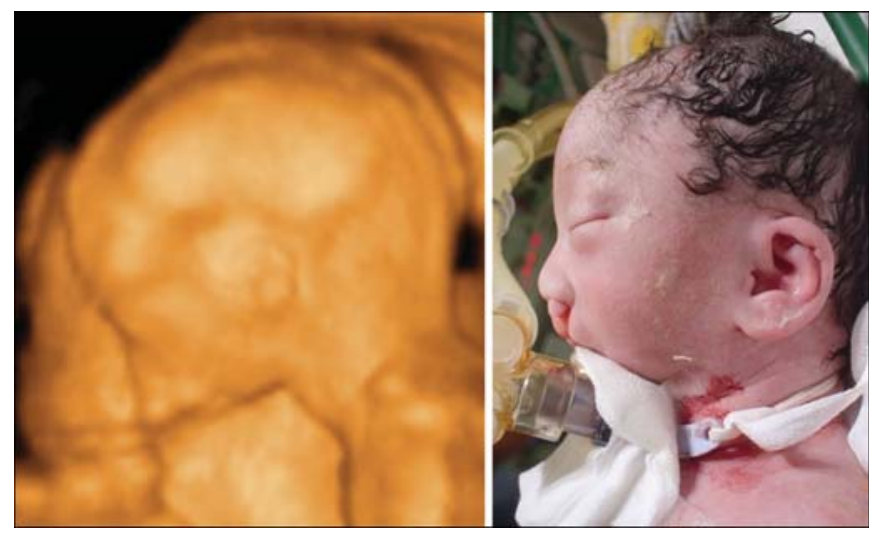

Fig. 9: Agnathia with cleft lip at 19 weeks. (left) 3D reconstructed lateral image of the fetal face at 19 weeks. (right) Postnatal facial appearance

greatly contribute to evaluation of fetal brain morphology. ${ }^{29}$ Figure 15 shows transvaginal 3D tomographic coronal, sagittal and axial ultrasound views of intracranial structure in a case of ventriculomegaly at 20 weeks of gestation. Thus, accurate assessment of brain pathology can be done by 3D ultrasound. Cortical development of fetal brain can

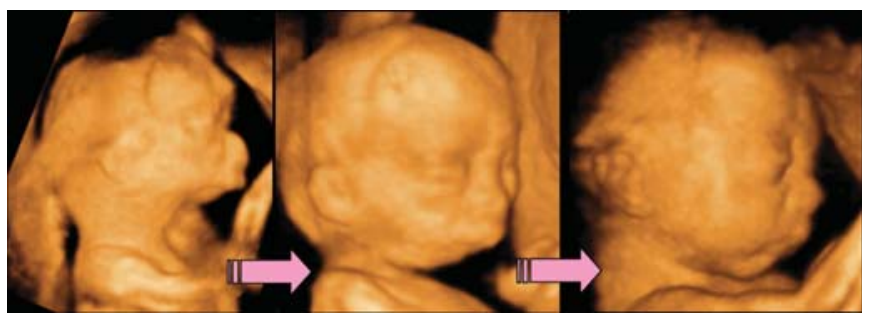

Fig. 10: Slow jaw development in a case of Pierre-Robin sequence during pregnancy. Serial 3D scan clearly reveals slow jaw development at 17 weeks (left), 20 weeks (middle) and 29 weeks (right) associated with Pierre-Robin sequence

also be visualized by 3D surface imaging, demonstrating gyral and sulcal development and migration disorder which had been difficult to be detected during pregnancy, can be depicted by 3D ultrasound. ${ }^{31}$ Figure 16 demonstrates the asymmetrical cortical development due to migration disorder by $2 \mathrm{D}$ ultrasound and 3D surface imaging. Thus, 3D ultrasound surface imaging is useful in objective assessment of brain surface. The cranial bone abnormality, seen in a case of encephalocele, can be also visualized by 3D ultrasound maximum mode imaging as shown in Figure 17. 


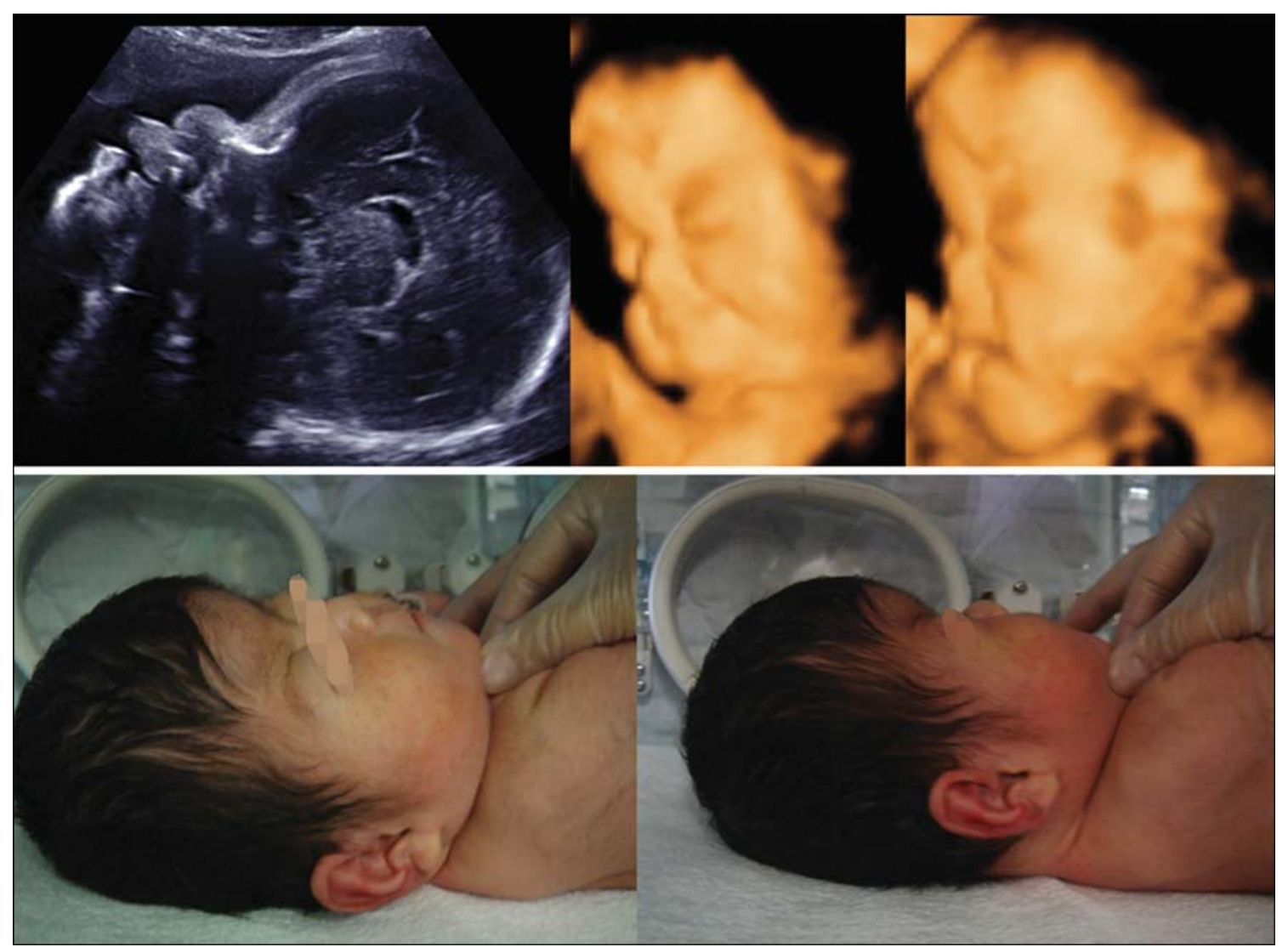

Fig. 11: Facial abnormality associated with Apert syndrome at $\mathbf{3 1}$ weeks. (upper left) 2D sagittal image of the fetal face. Note the marked frontal bossing and low nasal bridge. (upper middle and right) 3D reconstructed images of fetal face. Exophthalmos is clearly visualized. This facial appearance occurs due to craniosynostosis of coronal sutures seen in a case of Apert syndrome. (lower pictures) Postnatal facial appearance of the same baby

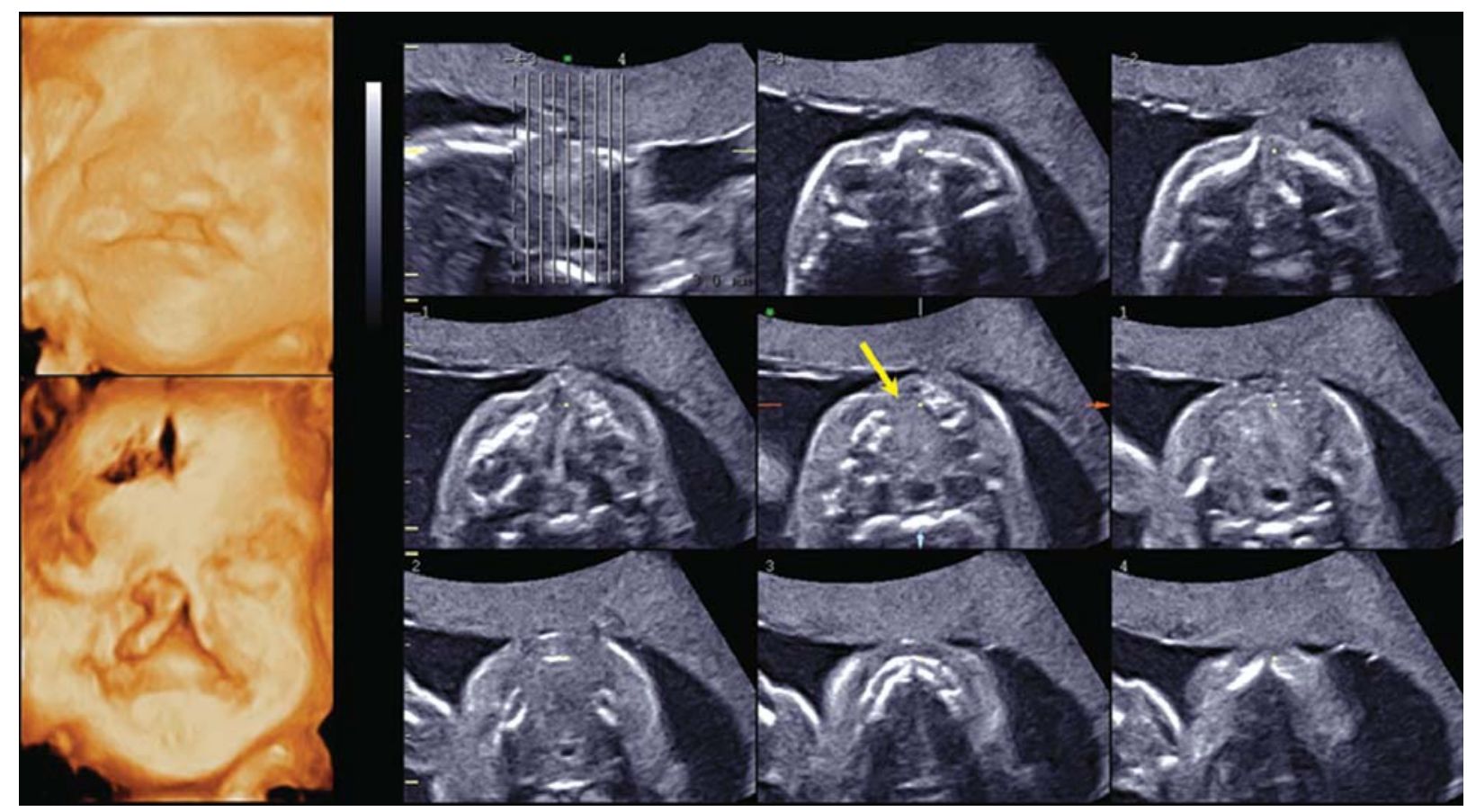

Fig. 12: Cleft lip and palate at 22 weeks. (upper left) Surface image of the fetal face. Left sided cleft lip and deformed nasal structure is clearly demonstrated. (lower left) 3D reconstructed image inside the oral cavity. Cleft palate is visualized. (right white and black) Tomographic ultrasound image of the anterior maxillary structure, indicating the evidence of alveolar cleft presence (arrow) 

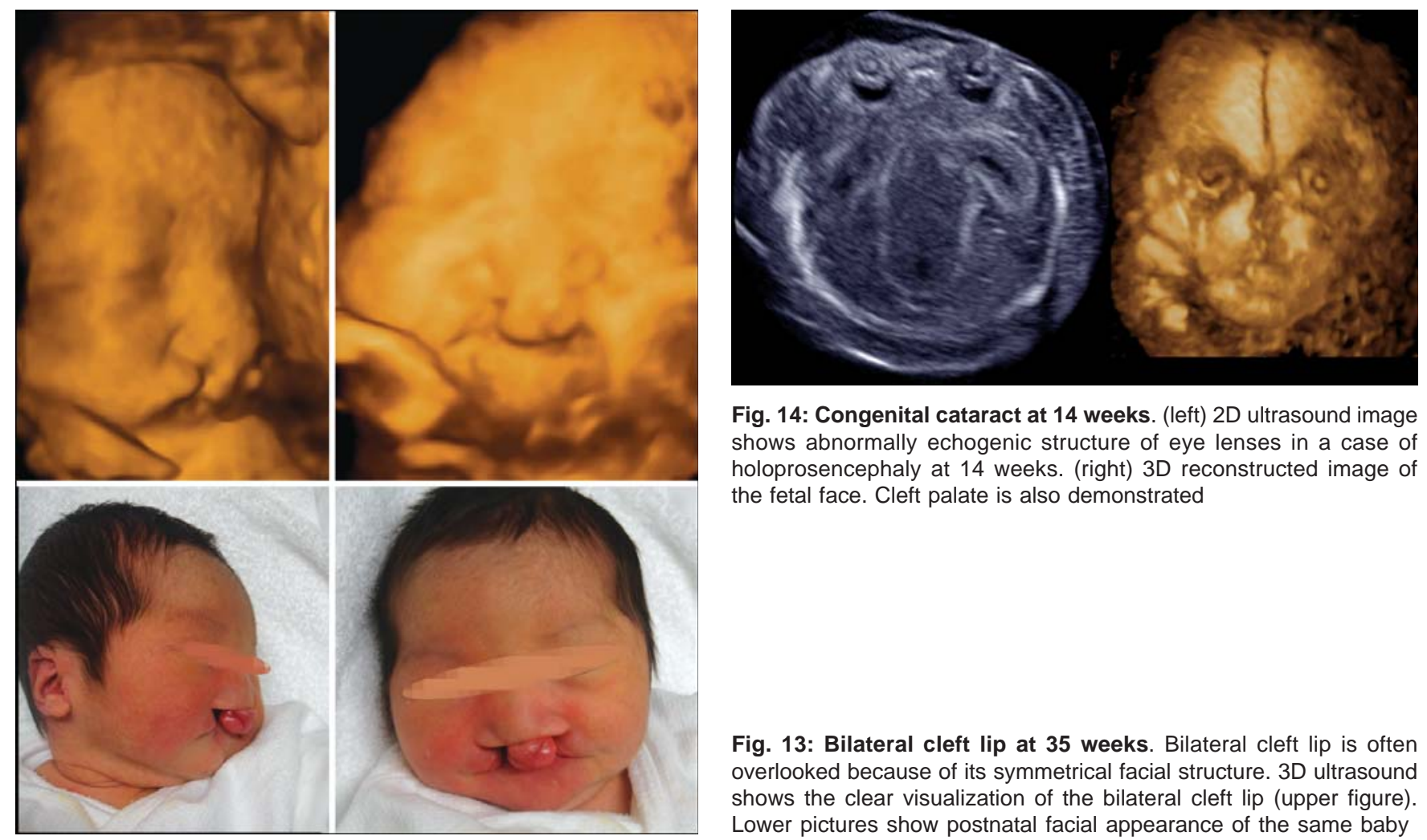

Fig. 14: Congenital cataract at 14 weeks. (left) 2D ultrasound image shows abnormally echogenic structure of eye lenses in a case of holoprosencephaly at 14 weeks. (right) 3D reconstructed image of the fetal face. Cleft palate is also demonstrated

Fig. 13: Bilateral cleft lip at 35 weeks. Bilateral cleft lip is often overlooked because of its symmetrical facial structure. 3D ultrasound shows the clear visualization of the bilateral cleft lip (upper figure). Lower pictures show postnatal facial appearance of the same baby

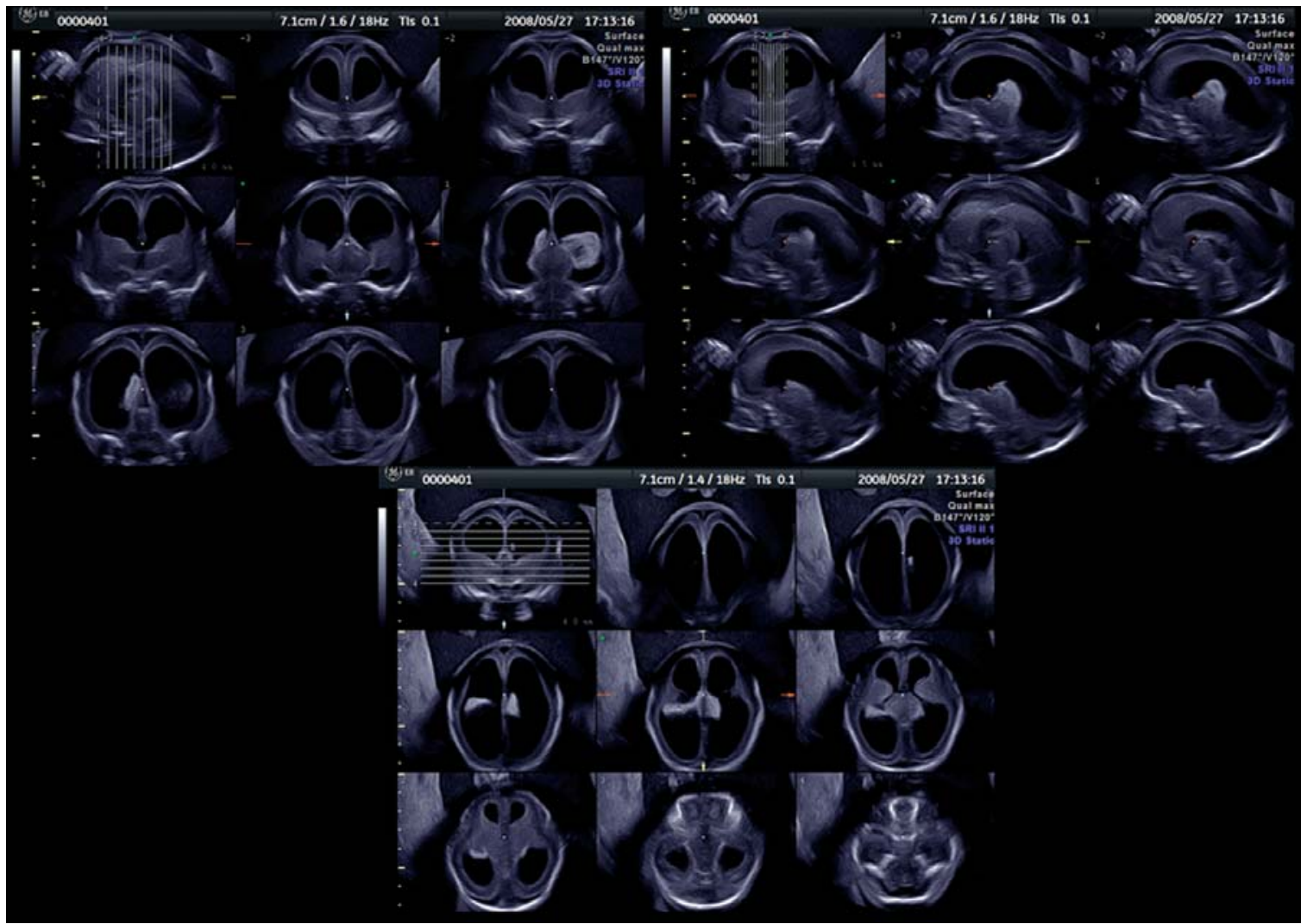

Fig. 15: Hydrocephalus at 20 weeks. Tomographic ultrasound images of coronal (upper left), sagittal (upper right) and axial (lower) views. Clear visualization of intracranial structure is acquired 

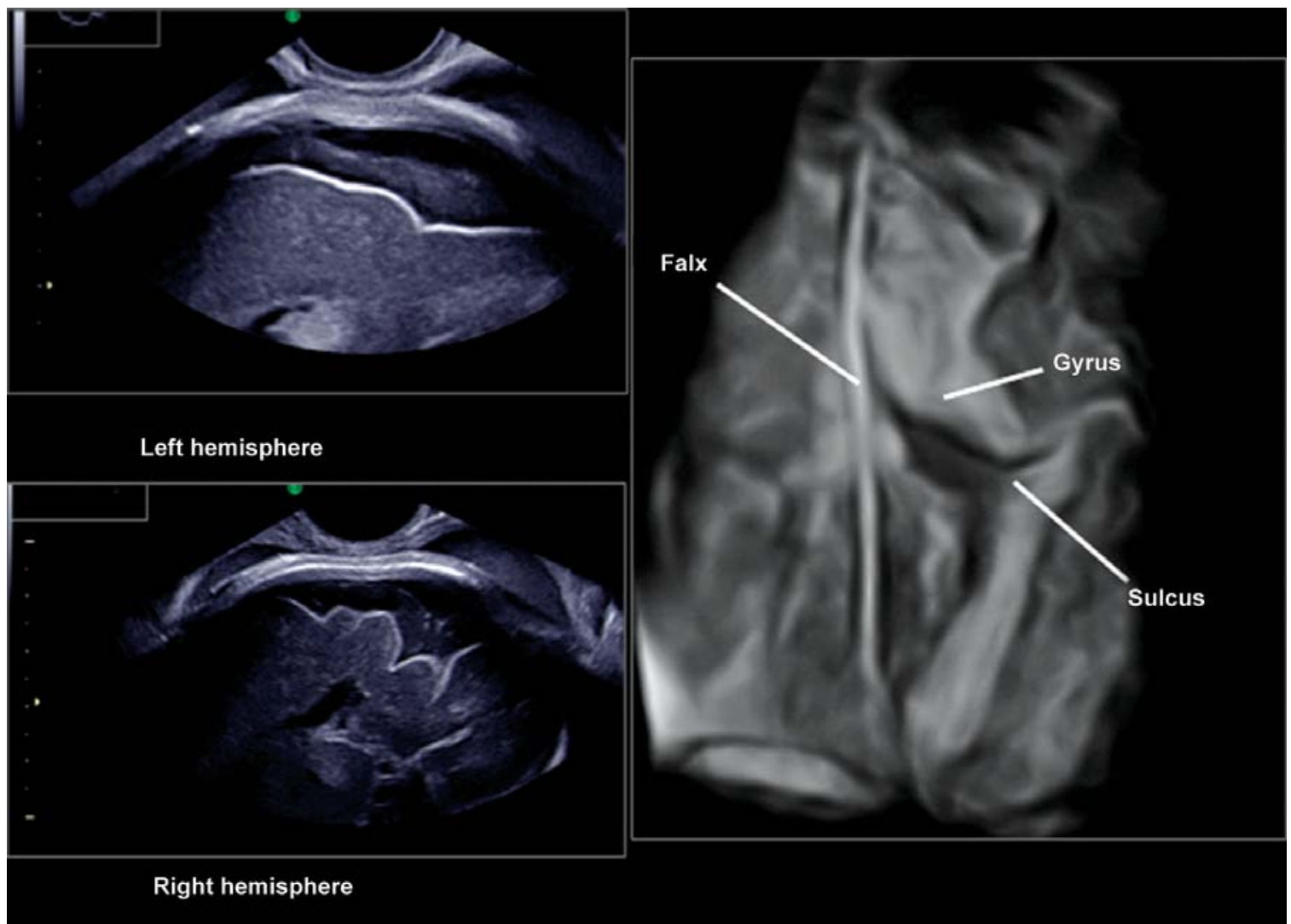

Fig. 16: Asymmetrical cortical formation at 29 weeks. Note the marked difference between left and right cortical appearance (left figures). Right figure demonstrated asymmetrical superficial image of the brain. Clear visualization of the brain surface with asymmetrical gyral/sulcal formation is acquired

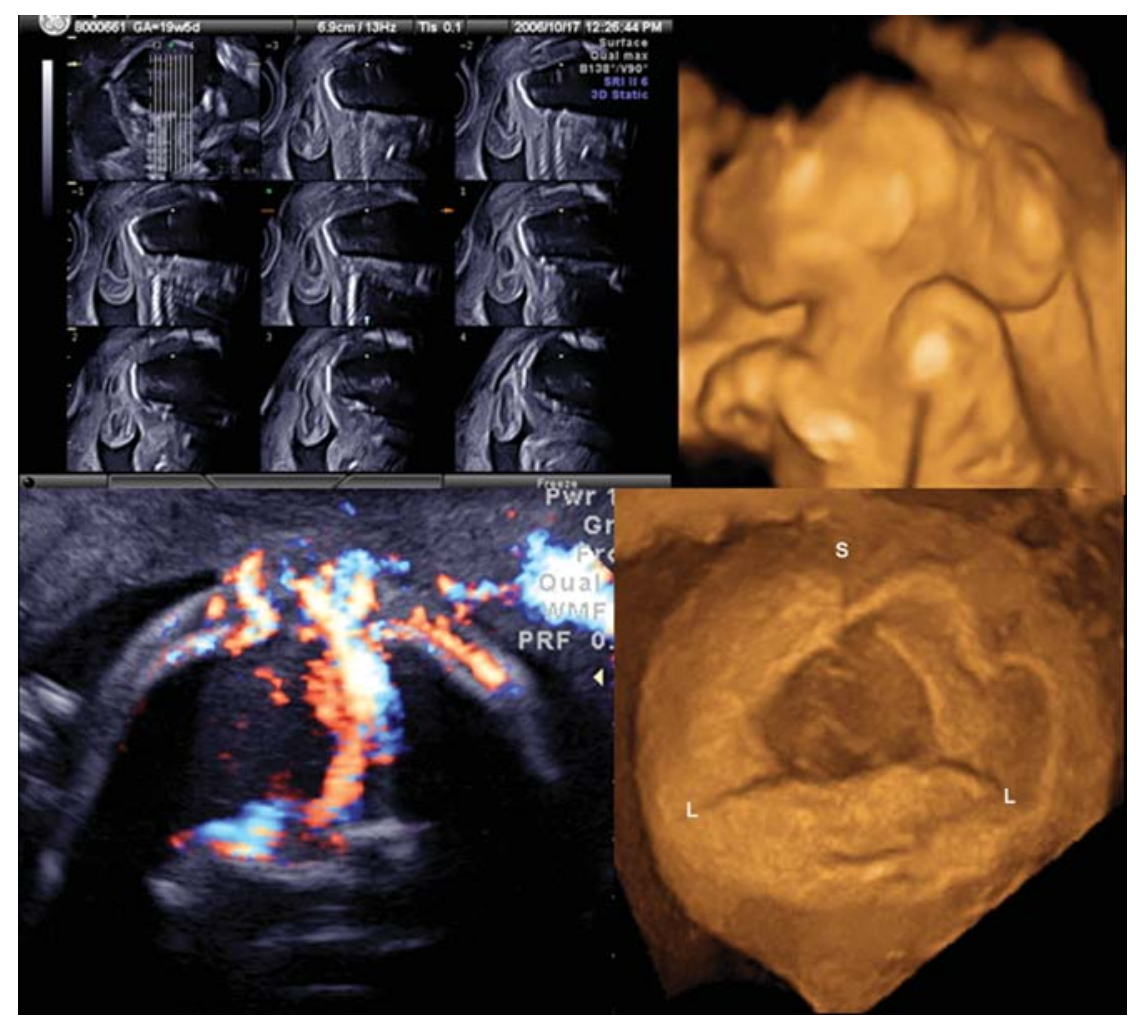

Fig. 17: Encephalocele at 19 weeks. (upper left) Tomographic ultrasound image of the encephalocele with small head. (upper right) 3D reconstructed lateral image of the fetus. Microcephaly with encephalocele is clearly demonstrated. (lower left) 2D bidirectional power Doppler image of the head. The cerebral arteries and veins are visualized between inside and outside of the brain. (lower right) The posteroanterior view of the cranial bones. The round shaped bony defect is demonstrated. S sagittal suture, L; lambdoid suture 


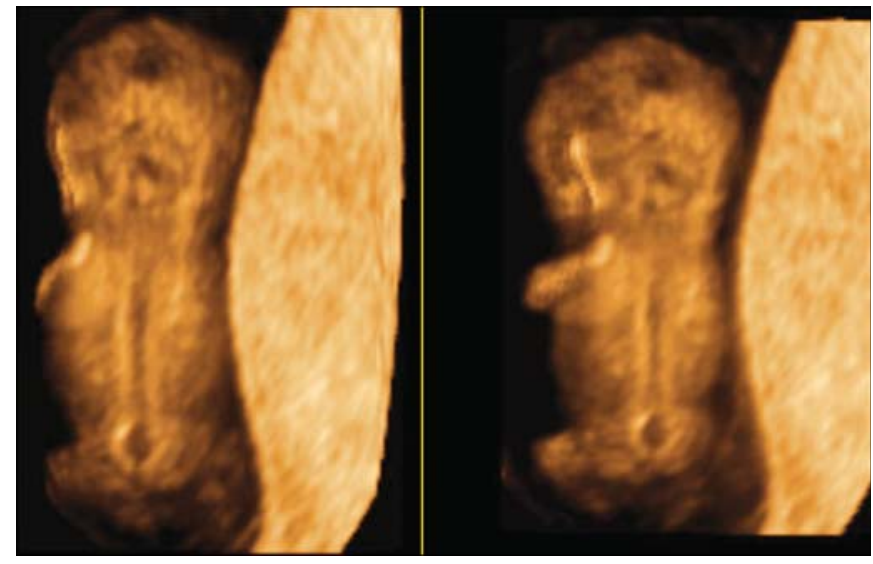

Fig. 18: Spina bifida at 9 weeks. Spina bifida is demonstrated as the widened spinal canal at the lumber part at as early as 9 weeks of gestation, however, it is difficult to differentiate myelomeningocele from meningocele at this stage because spinal cord cannot be visualized

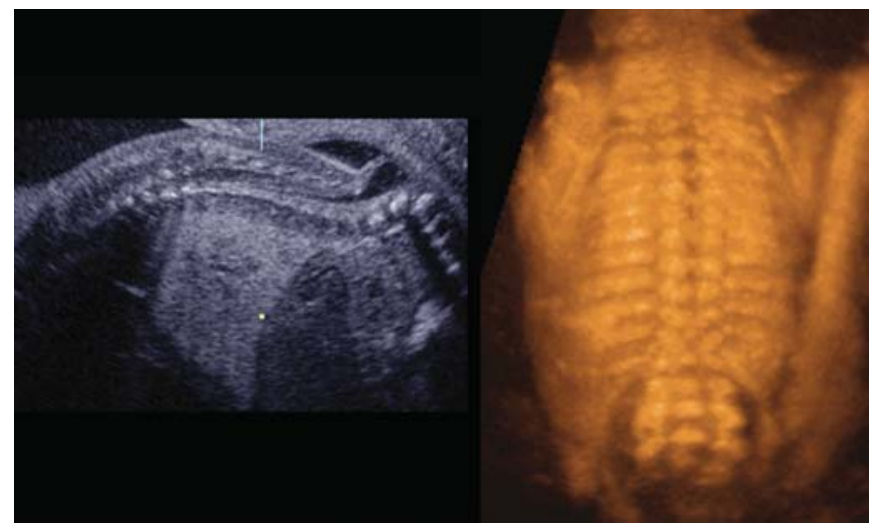

Fig. 19: Myelomeningocele with kyphosis at 20 weeks. (left) Sagittal image of the fetal trunks from 3D orthogonal view. Severe kyphosis and myelomeningocele is seen. (right) $3 \mathrm{D}$ reconstructed image of the fetal back. The huge mass is seen from $L 1$ to $S$ region. The ribs are clearly seen and the level of spina bifida is easily understandable

\section{Vertebra and Spinal Cord Abnormalities}

Spina bifida is the most common anomaly of the central nervous system. It is often detected during the second and third trimesters. However, the fundamental basis for this anomaly is a failure of the neural tube to close during early embryonic age. Most reports of the diagnosis of spina bifida in utero have occurred after 12 weeks of gestation. Blaas et $\mathrm{al}^{32}$ reported an early diagnosis using 2D and 3D ultrasound before 10 weeks of gestation. Figure 18 shows the early diagnosis of spina bifida in a case of OEIS complex (omphalocele, bladder exstrophy, imperforate anus, spina bifida) at 9 weeks of gestation and Figure 19 demonstrates myelomeningocele at 20 weeks. The vertebral bony structure can be depicted by 3D ultrasound for better understanding the level of spina bifida. Vertebral scoliosis is often seen in cases of limb body wall complex (Fig. 20) or cases of hemivertebra as shown in Figures 21 and 22. In hemivertebral cases, asymmetrical rib number can be also demonstrated. Figure 23 demonstrates an abnormally retroflexed fetus seen in a case of Down's syndrome. Other rare vertebral abnormalities are shown in Figures 24 and 25. Figure 24 shows fused vertebral bodies in a thoracic part seen in a case of trisomy 18 and Figure 25 shows the segmental spinal dysgenesis, characterized by focal agenesis or dysgenesis of the lumbar or thoracolumbar spine, with focal abnormality of the underlying spinal cord and nerve roots. ${ }^{33}$

\section{Chest-abdominal Abnormalities}

Congenital diaphragmatic hernia (CDH) occurs in 1 of every 2000-4000 live births and accounts for 8\% of all major congenital anomalies. ${ }^{34}$ There are three types of CDH; posterolateral or Bochdalek hernia (occurring at approximately 6 weeks' gestation), the anterior Morgagni hernia, and a hiatus hernia. The left-sided Bochdalek hernia occurs in approximately $90 \%$ of cases. Left-sided hernias allow herniation of both small and large bowel as well as intra-abdominal solid organs into the thoracic cavity. Early diagnosis of $\mathrm{CDH}$ in the first trimester has been reported. ${ }^{35}$ Figure 26 shows the tomographic ultrasound imaging of Bochdalek hernia at 16 weeks. Early diagnosis of this defect is important for the option of fetal treatment. Congenital cystic adenomatoid malformation (CCAM, Fig. 27) is a benign mass of abnormal lung tissue, located usually on one section of the lung. This condition is caused by overgrowth of abnormal lung tissue that may form fluid filled cysts and have no function of normal lung tissue. Early diagnosis of CCAM by 3D ultrasound was reported. ${ }^{36}$ Pleural effusion and ascites (Fig. 28) can be easy diagnosed by both 2D/3D ultrasound. In cases of pleural effusion, the lung is floated inside the fluid, whereas, in cases of pericardiac effusion, the lungs are oppressed to posterior potion of the chest (Fig. 29). Umbilical hernia is often associated with chromosomal abnormality or other syndromic diseases. Figure 30 shows a huge umbilical hernia at 12 weeks.

\section{RENAL AND URINARY ABNORMALITIES}

Hydronephrosis (Fig. 31) occasionally occurs during pregnancy. The causes are vary, obstruction or stenosis of 


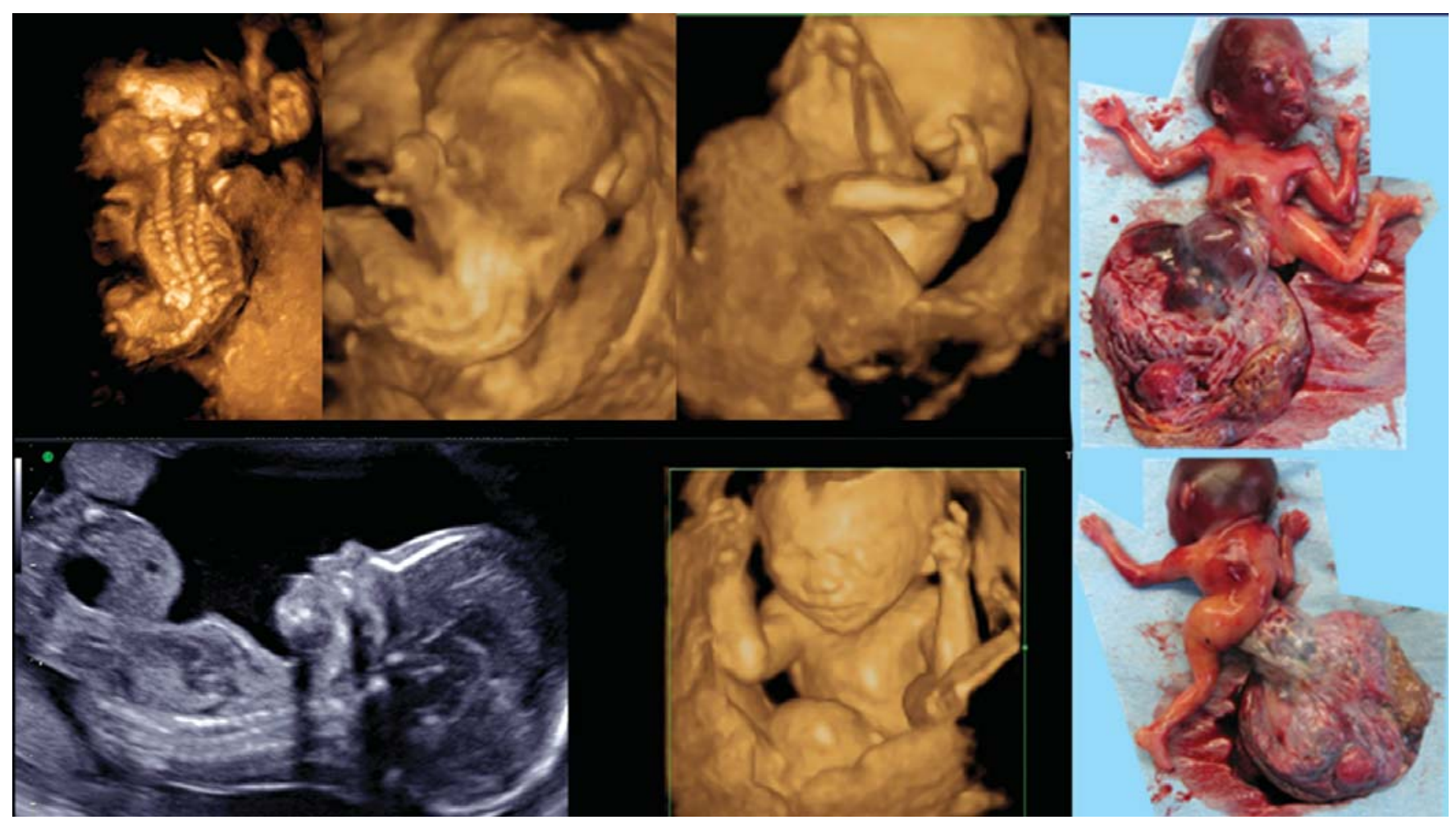

Fig. 20: Vertebral scoliosis associated with limb body wall complex at 20 weeks. Severe vertebral scoliosis, abnormal leg position with one leg missing, umbilical hernia with short umbilical cord are clearly demonstrated by 2D/3D ultrasound. Right two figures show the appearance of the aborted fetus

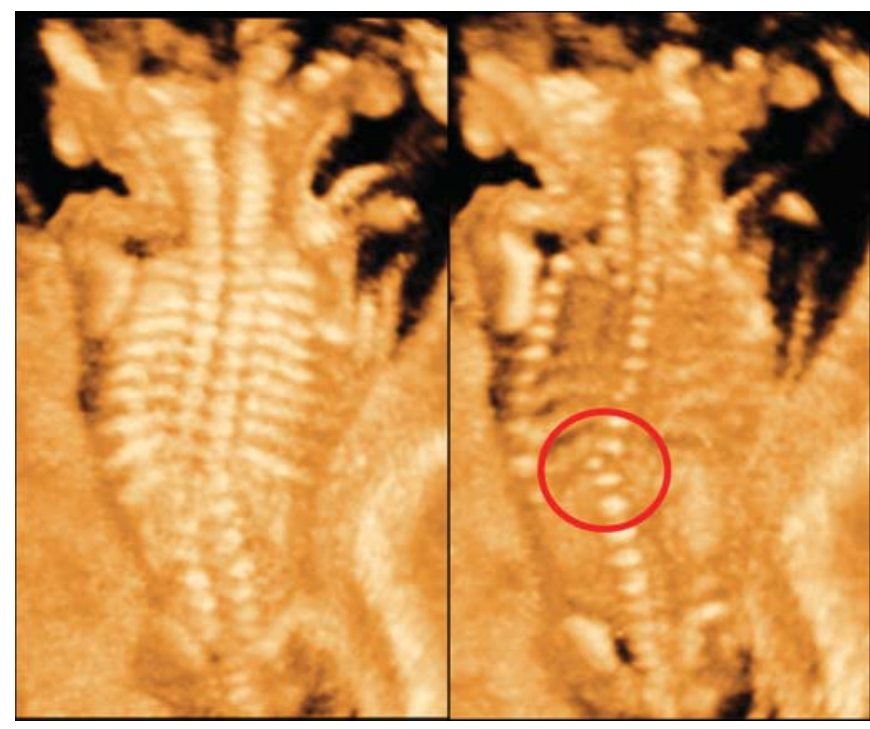

Fig. 21: Hemivertebra at 19 weeks. (left) 3D maximum mode image of the fetal back. Scoliosis with asymmetrical number of ribs (left;11 ribs, right; 10 ribs) is clearly demonstrated. (right) 3D image of the vertebral body layer reveals Th12 hemivertebra (red circle) and this hemivertebra should be the cause of scoliosis

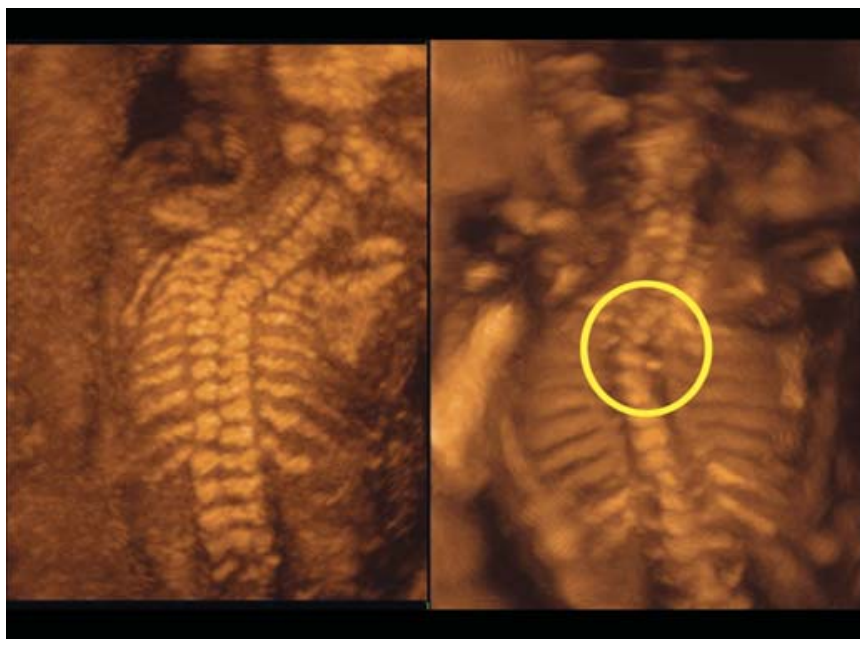

Fig. 22: Three levels hemivertebra at 20 weeks. (left) 3D maximum mode image of the fetal back. Severe scoliosis with asymmetrica number of ribs (left;12 ribs, right; 9 ribs) is clearly demonstrated. (right) 3D image of the vertebral body layer reveals three levels hemivertebrae (Th1-Th3, yellow circle) 


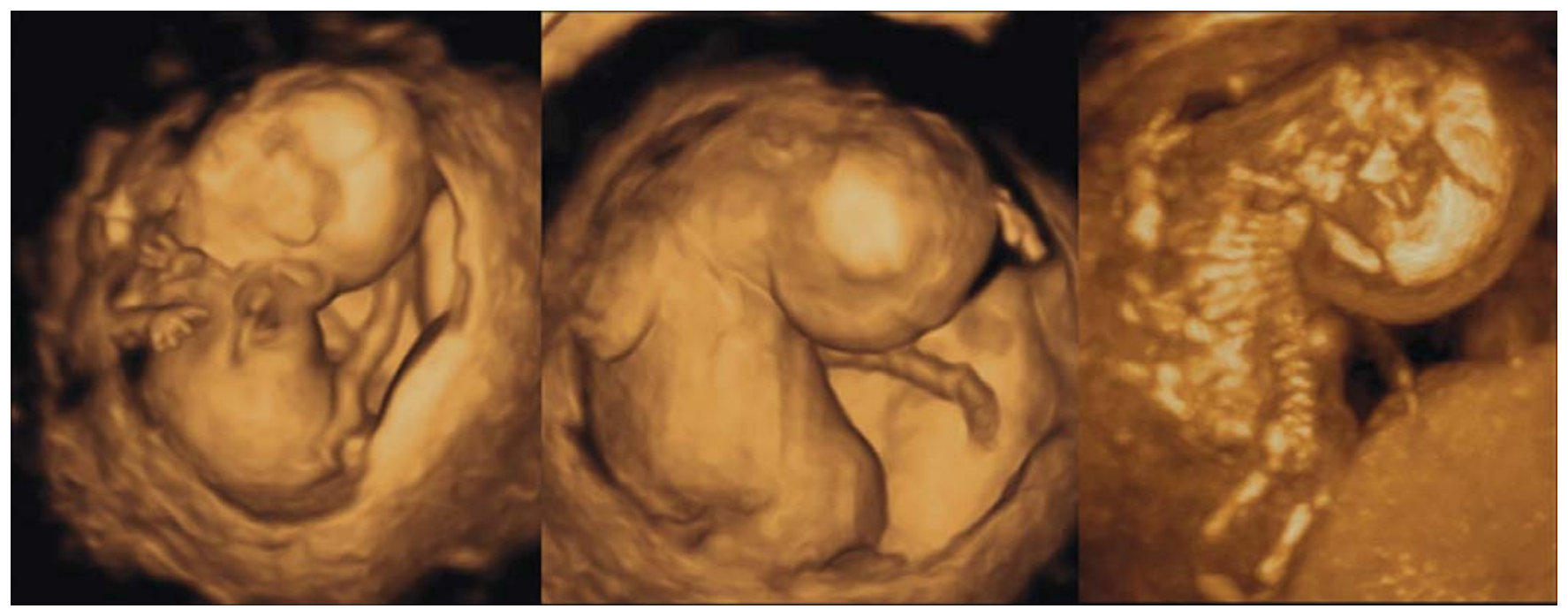

Fig. 23: Abnormally retroflexed fetus at 14 weeks. 3D surface images (left and middle) demonstrate abnormally retroflexed fetus. Maxim mode (right) shows fetal bony structure. This rarely abnormal-looking fetus died in utero and trisomy 21 was confirmed

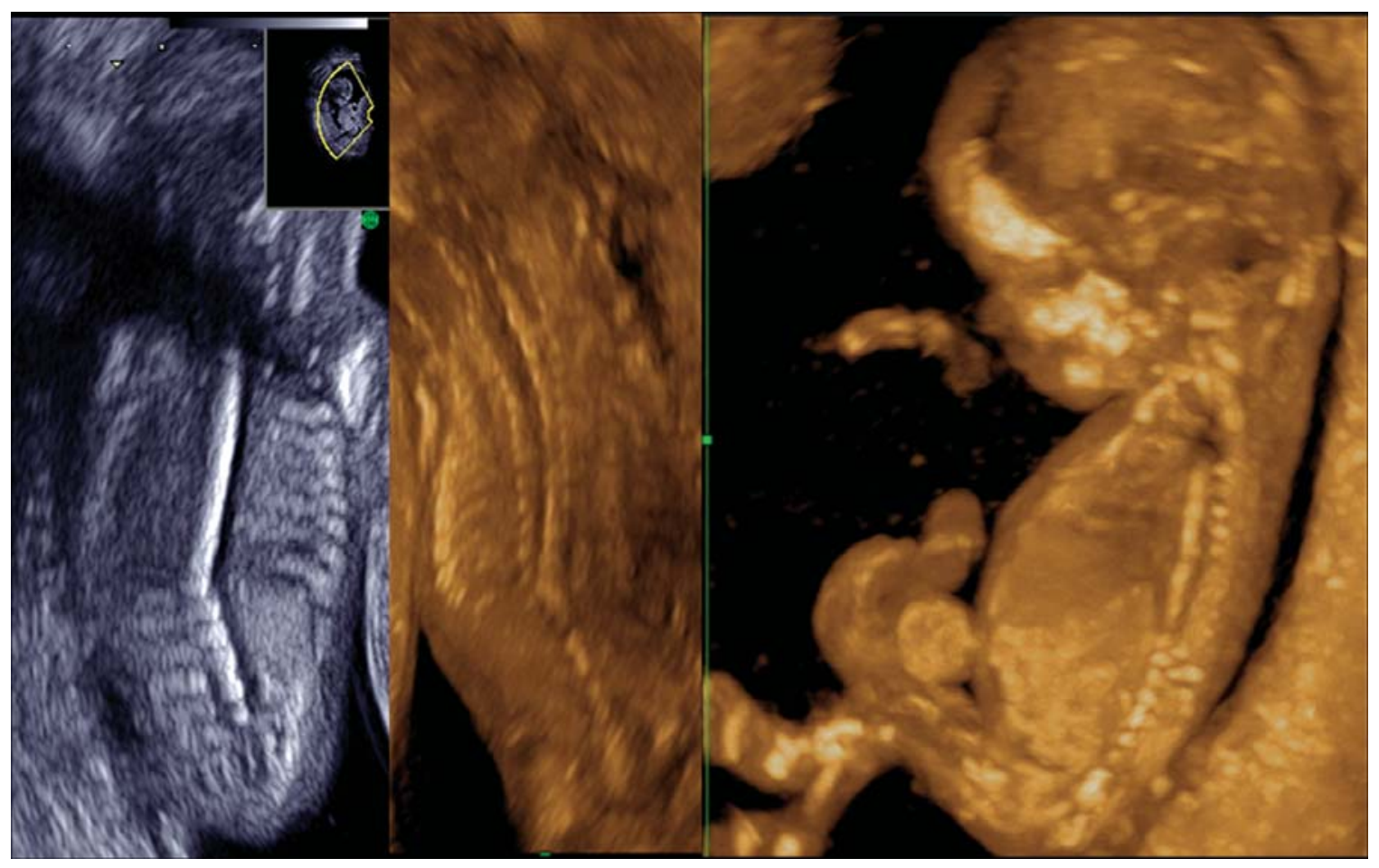

Fig. 24: Fused vertebra with scoliosis at 13 weeks. (left) 2D image of the vertebra. Fused thoracic vertebrae forms stick-like appearance. 3D reconstructed coronal (middle) and sagittal (right) images. Trisomy 18 was confirmed thereafter 


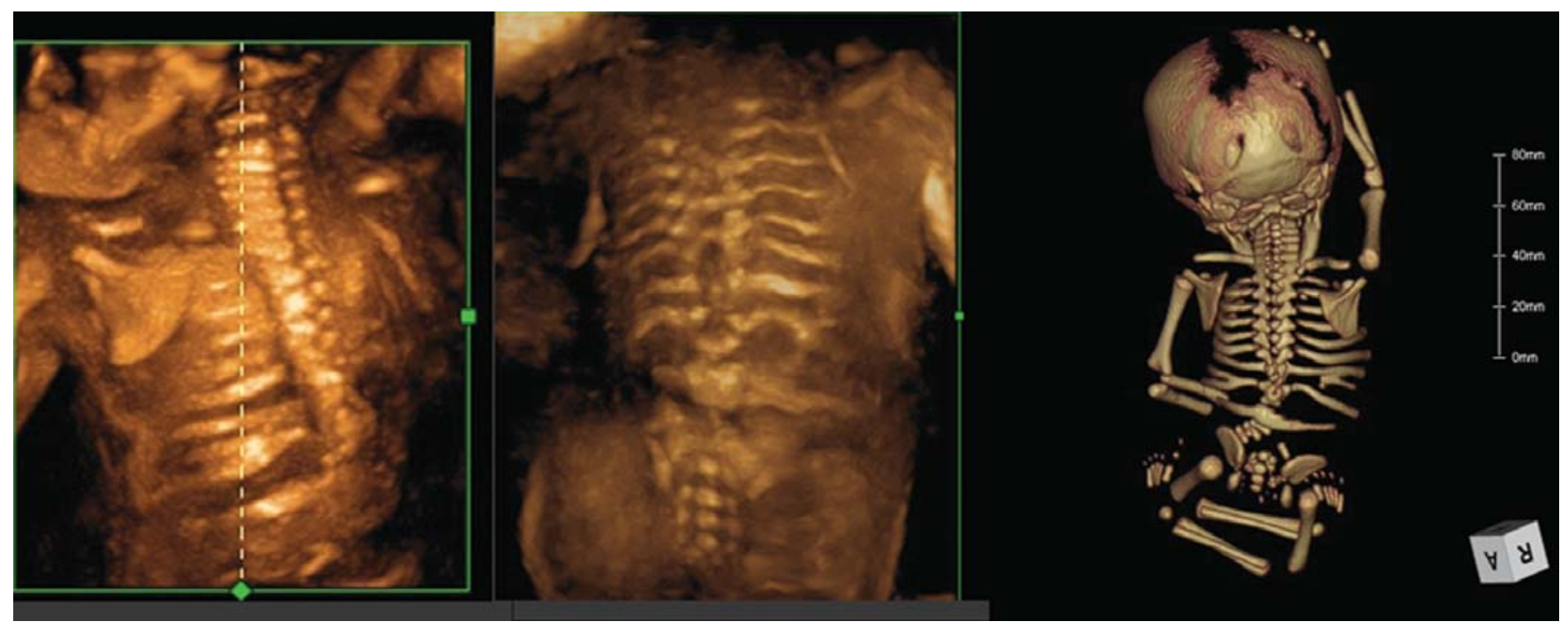

Fig. 25: Segmental spinal dysgenesis at 27 weeks (3D ultrasound and 3D-CT images). (left and middle) 3D US reconstructed images. Note the focal dysgenesis of the thoracolumbar vertebra, with rib abnormality which indicates features of segmental spinal dysgenesis. (right) 3D-CT scan image of the same fetus. Clear visualization of the bony structure is acquired

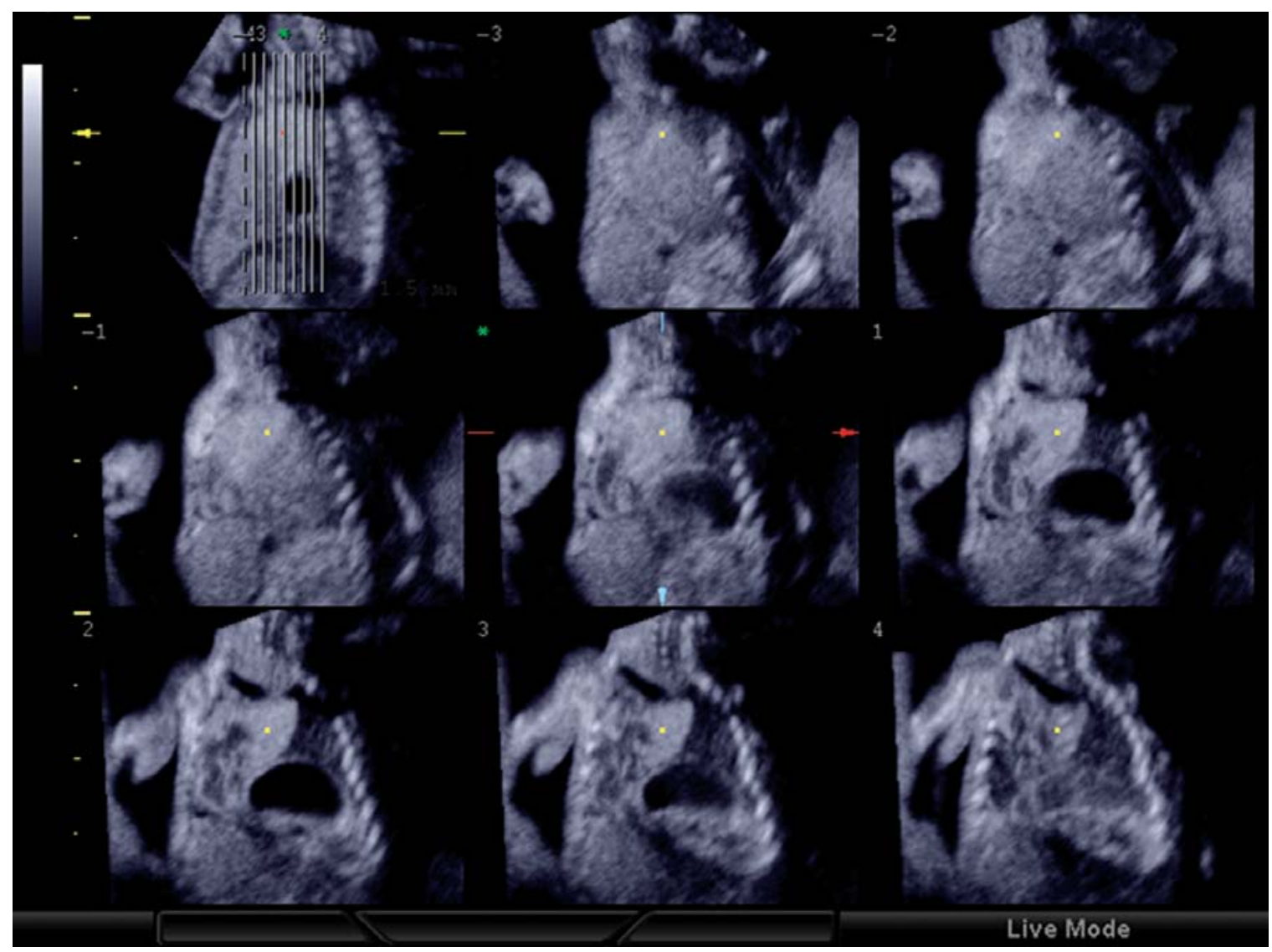

Fig. 26: Congenital diaphragmatic hernia at 16 weeks. Tomographic ultrasound image. Typical Bochdalek hernia is seen. Tomographic image clearly shows oppressed and hypoplastic left lung, heart replacement to the right, and the stomach inside thoracic space 


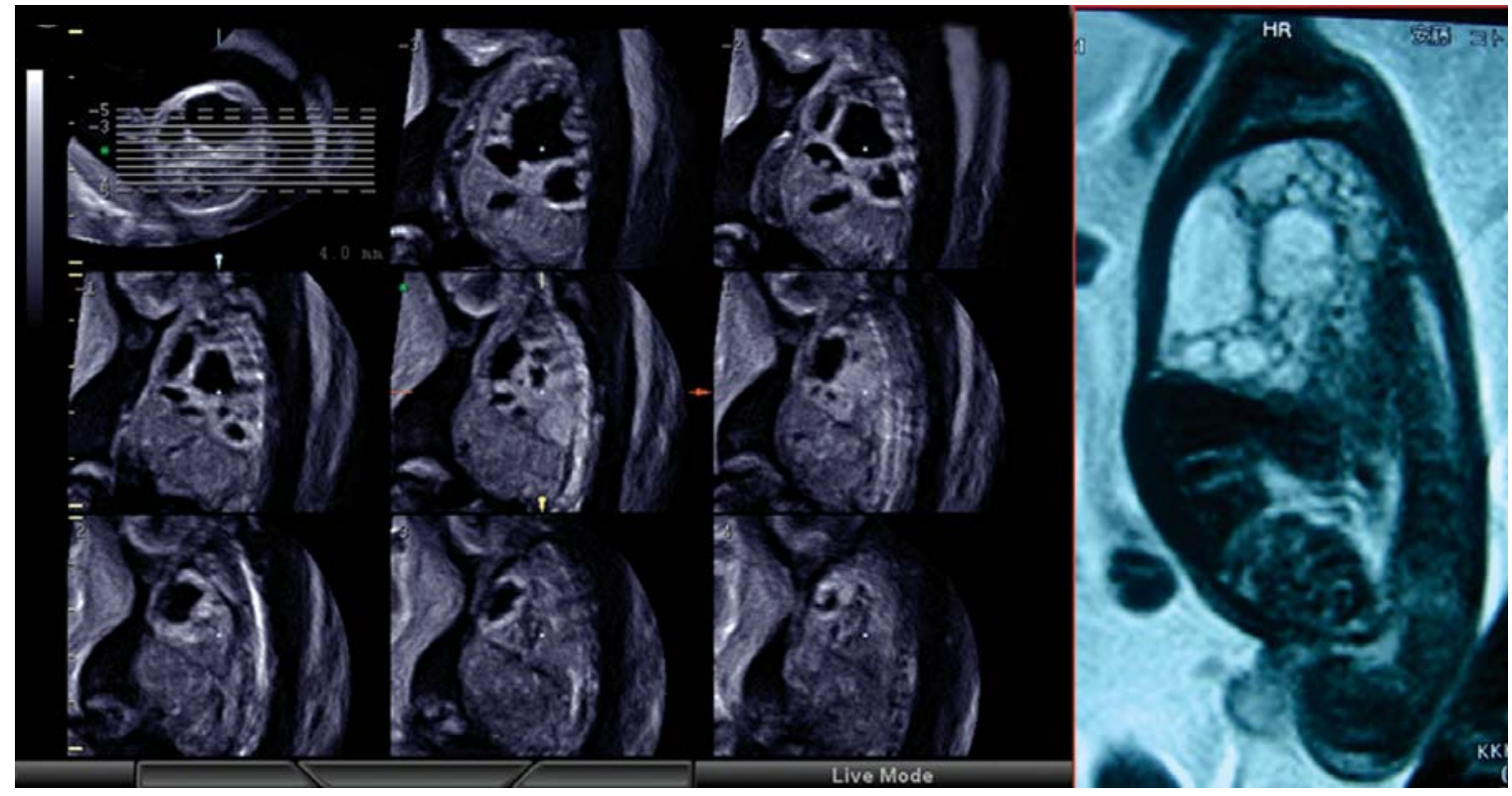

Fig. 27: Congenital cystic adenomatoid malformation (CCAM) at 24 weeks. (left) Tomographic ultrasound sagittal image of fetal chest. Multiple cysts with different size are seen. (right) MR image of the same fetus

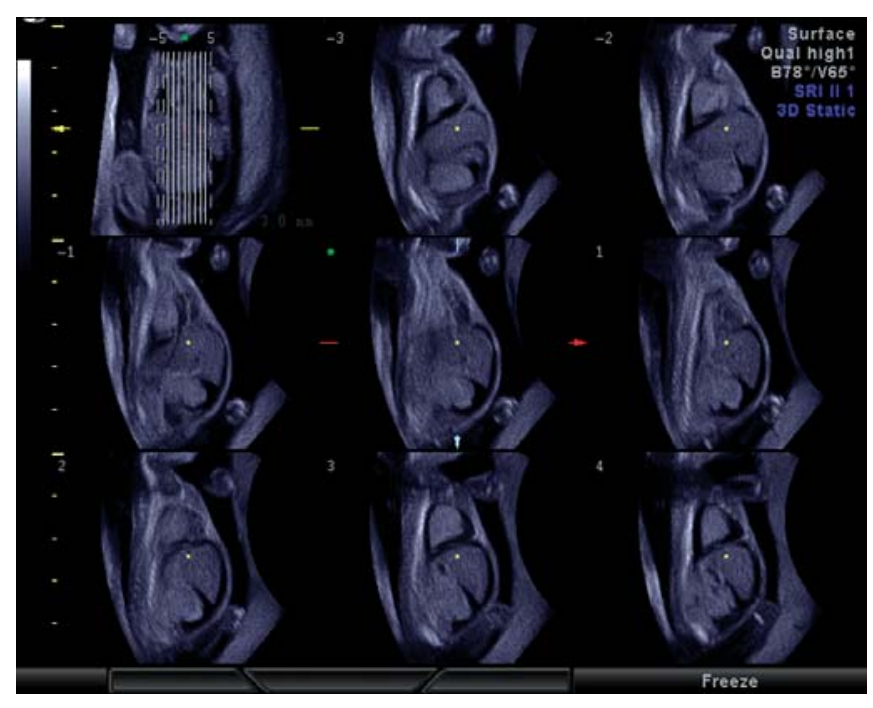

Fig. 28: Pleural effusion and ascites at 19 weeks. Tomographic ultrasound sagittal image of the fetal trunk. Fluid collection in both chest and abdomen are clearly demonstrated

ureters, posterior urethral valves (Fig. 32) or others. Multicystic dysplastic kidney (MCDK) is a form of renal dysplasia characterized by the presence of multiple cysts of varying size in the kidney and the absence of a normal pelvocaliceal system. Fetal MCDK occasionally decreased its size during pregnancy and it is reported that MCDK size tends to decrease during the first 30 postnatal months. ${ }^{37}$

\section{Limb Abnormalities}

Limb abnormalities can occur as isolated findings or as one component of a syndrome or sequence. However, only 5\%

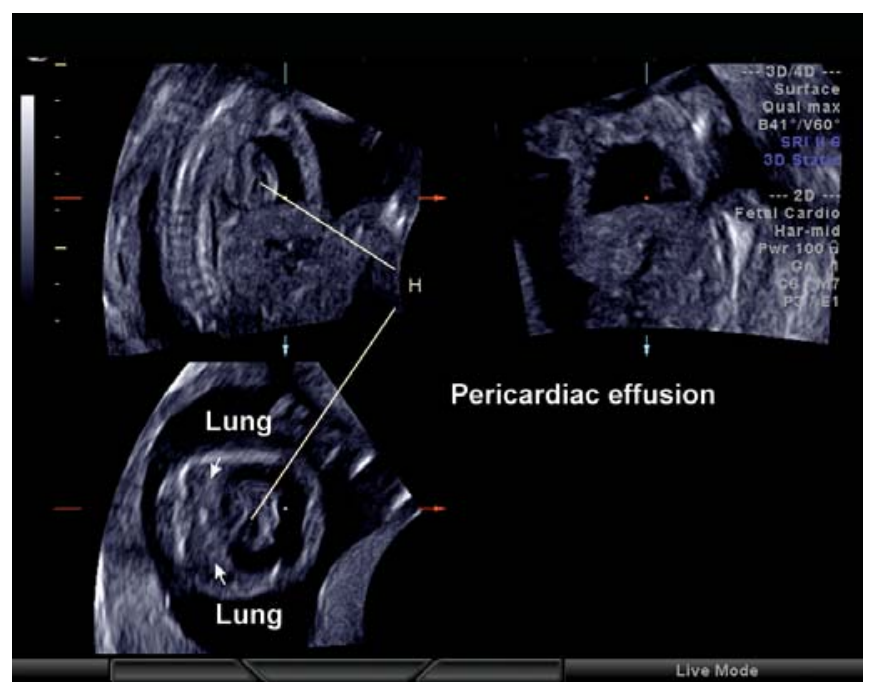

Fig. 29: Pericardiac effusion at 19 weeks. Three orthogonal view of the fetal chest. Due to fluid collection inside epicardium, the lungs are oppressed to posterior potion of the chest

of congenital hand anomalies occur as part of a recognized syndrome. ${ }^{38}$ Figure 34 shows thin limbs with no other abnormalities in a case of triploidy. Figure 35 demonstrates $3 \mathrm{D}$ ultrasound images and postmortem pictures in a case of lethal pterygium syndrome. Pterygium is used to describe webbing of the skin across the joint. The term means "winglike". Limb pterygia at birth indicates an abnormal developmental process probably occurring in the first trimester and involving reduced mobility of the webbed limb. Prenatal diagnosis in the first trimester was reported. ${ }^{39}$ Figure 36 shows unilateral forearm and thumb abnormality 


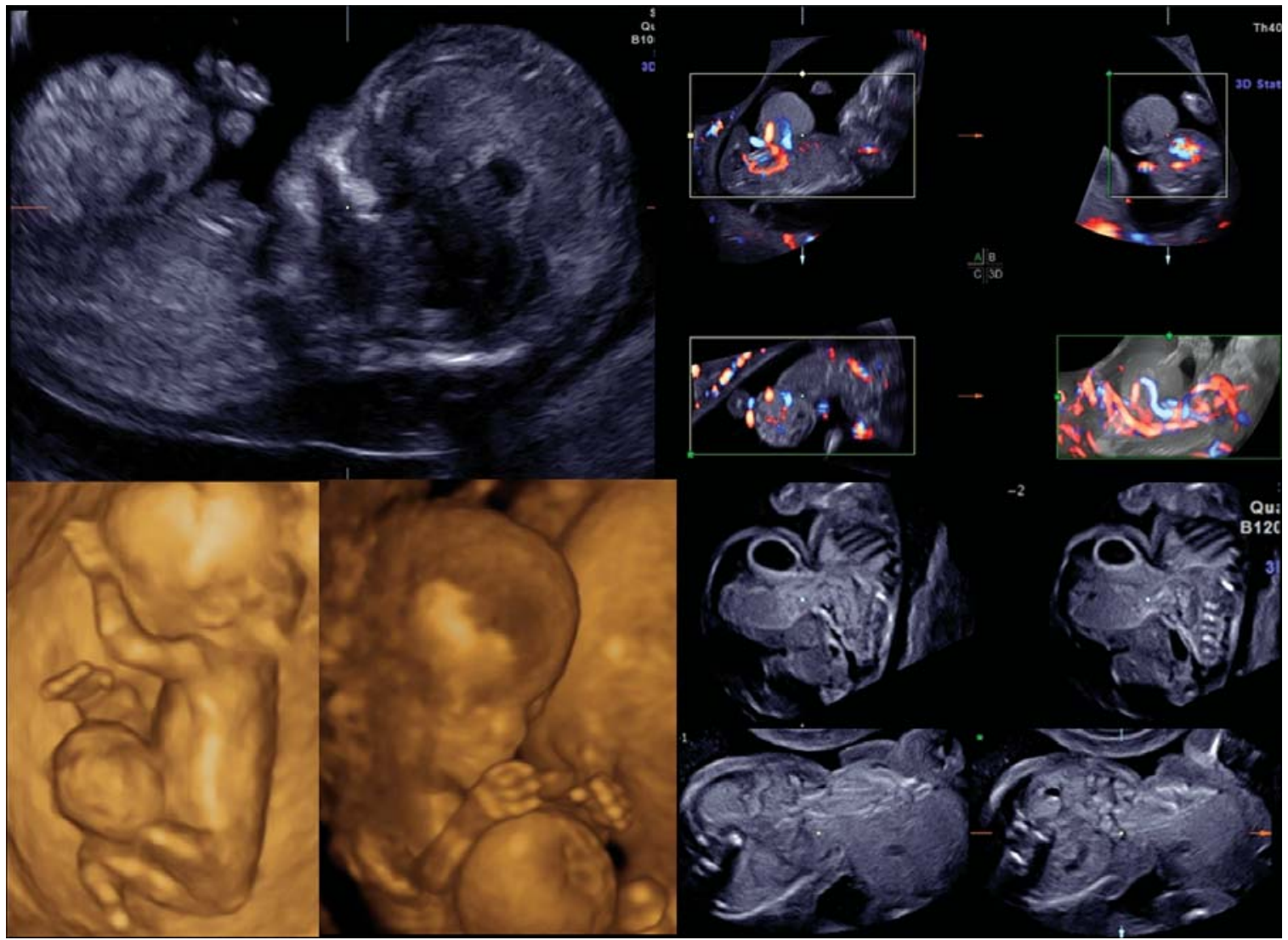

Fig. 30: Huge omphalocele at 12 weeks. (upper left) Sagittal image from 3D orthogonal view. Increased nuchal translucency is seen. (upper right) Three orthogonal view and reconstructed image of the fetal circulation. Because of the ectopic liver, the umbilical vein and ductus venosus run outside the body toward the heart inside the body. The ductus venosus reversed flow was seen in this case. (lower left) 3D reconstructed images. (lower right) Four selected images from tomographic ultrasound images, demonstrating the relation of ectopic organs and inside organ. After confirming normal chromosome and no other associated anomalies were confirmed, parents decide to continue pregnancy. Postnatal surgery was successful and postoperative course has been favorable

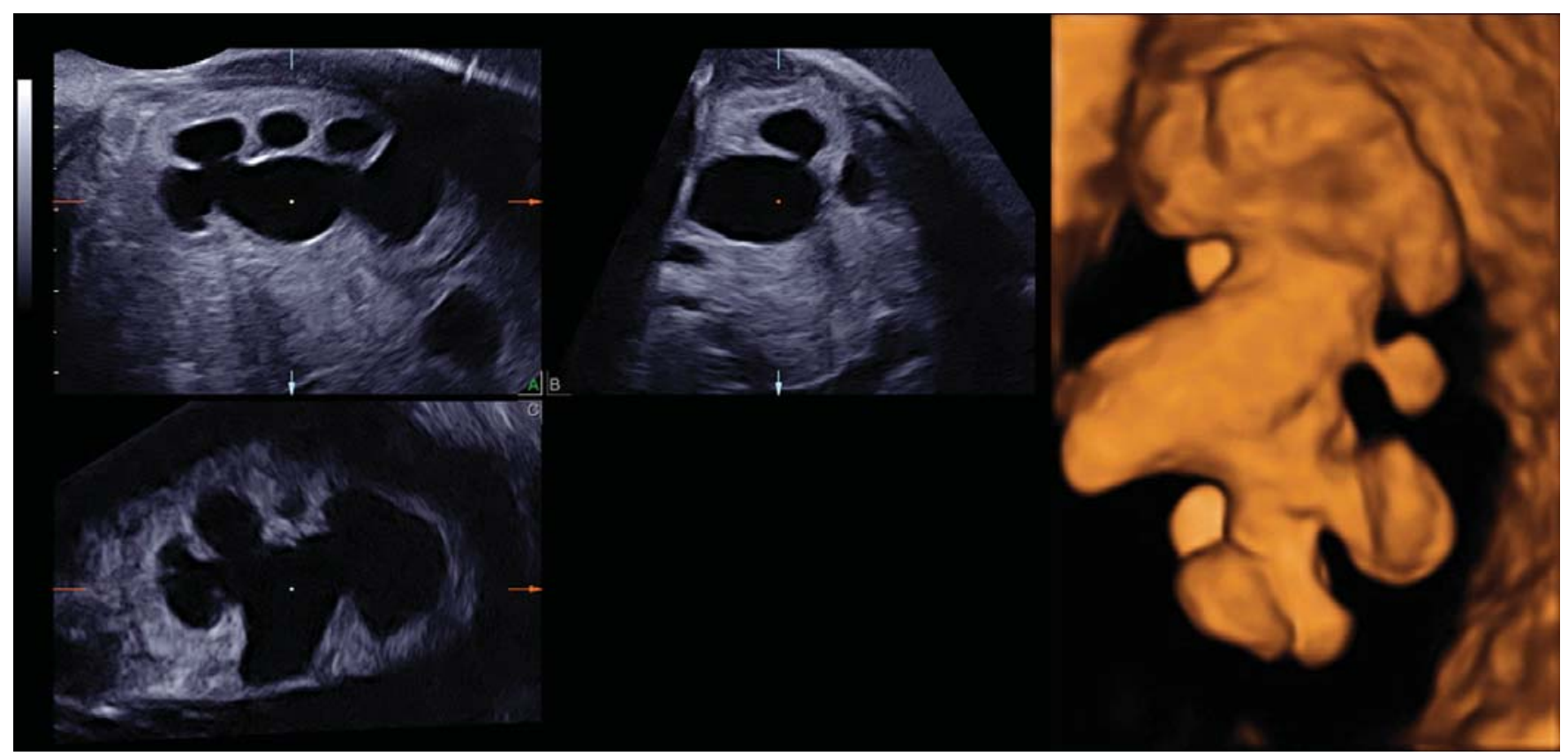

Fig. 31: Mild hydronephrosis at 27 weeks. Three orthogonal view (left) and 3D reconstructed inverted image of the renal pelvis (right) 


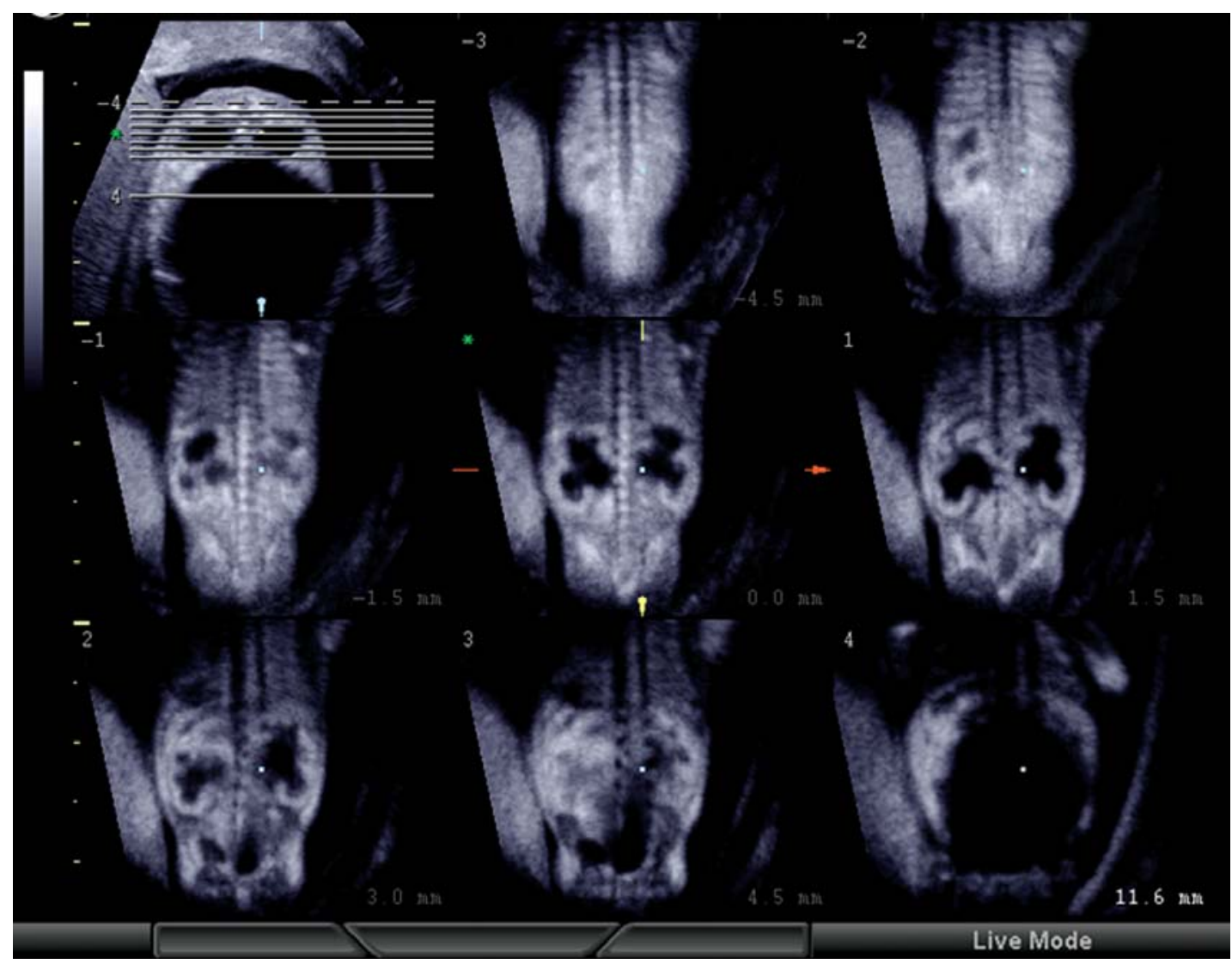

Fig. 32: Bilateral hydronephrosis due to posterior urethral valve stenosis at 15 weeks. Tomographic ultrasound coronal image of the bilateral kidneys. Bilateral hydronephrosis with huge bladder occurred due to posterior urethral valve stenosis. Vesicoamniotic shunt at 17 weeks was successfully performed in this case and postnatal course was favorable

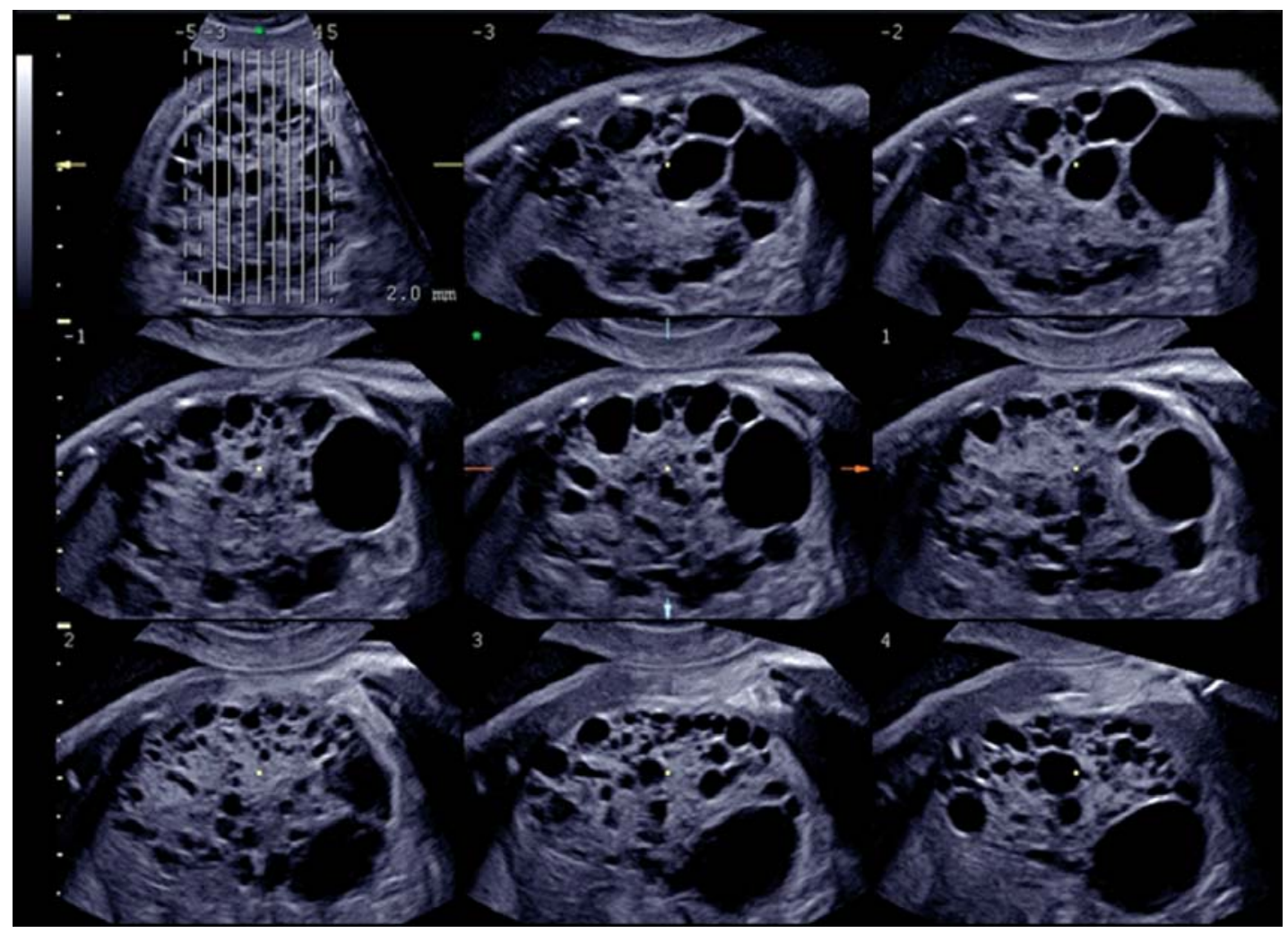

Fig. 33: Multicystic dysplastic kidney (MCDK) at 22 weeks. Tomographic ultrasound image of unilateral MCDK. Note the numerous intrarenal cysts in different size are demonstrated 


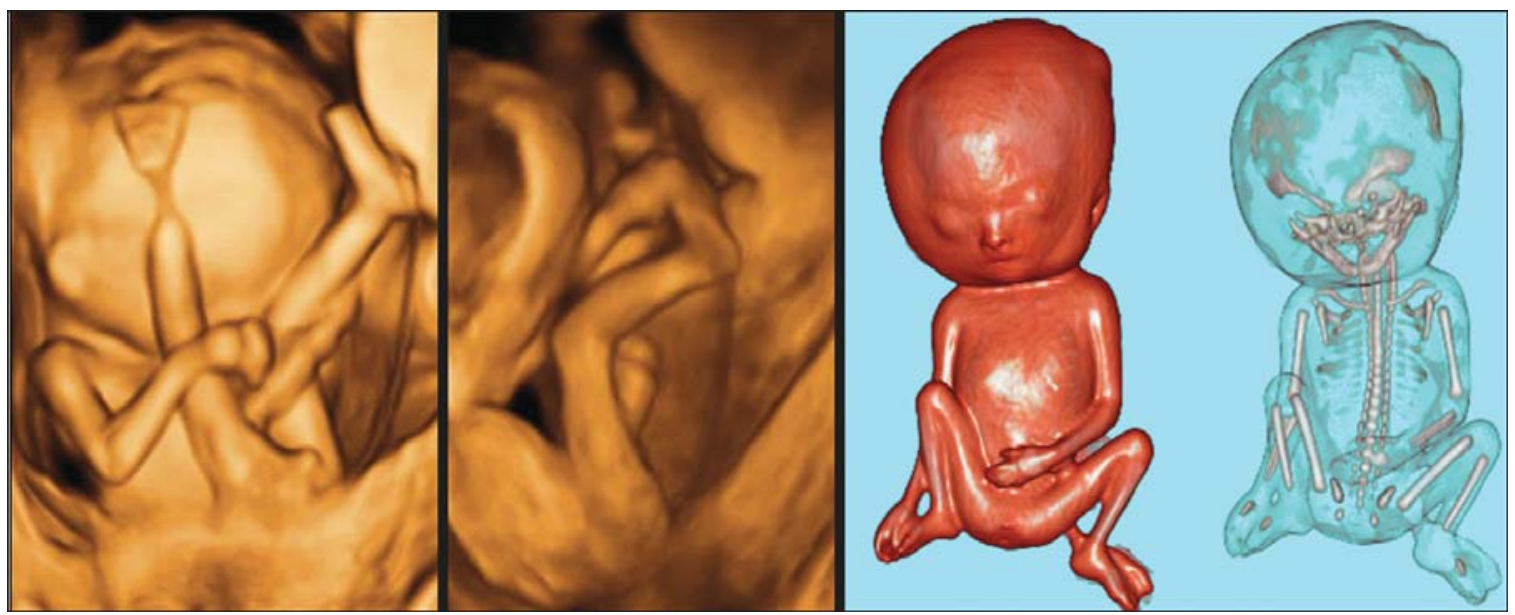

Fig. 34: Thin limbs in a case of triploidy at 17 weeks. (upper) 3D US reconstructed images. Small for date baby with abnormal proportion, large head and thin limbs and trunk, is demonstrated. (lower) Postmortem 3D-CT scan image of surface anatomy (left) and bony structure (right) of the same baby
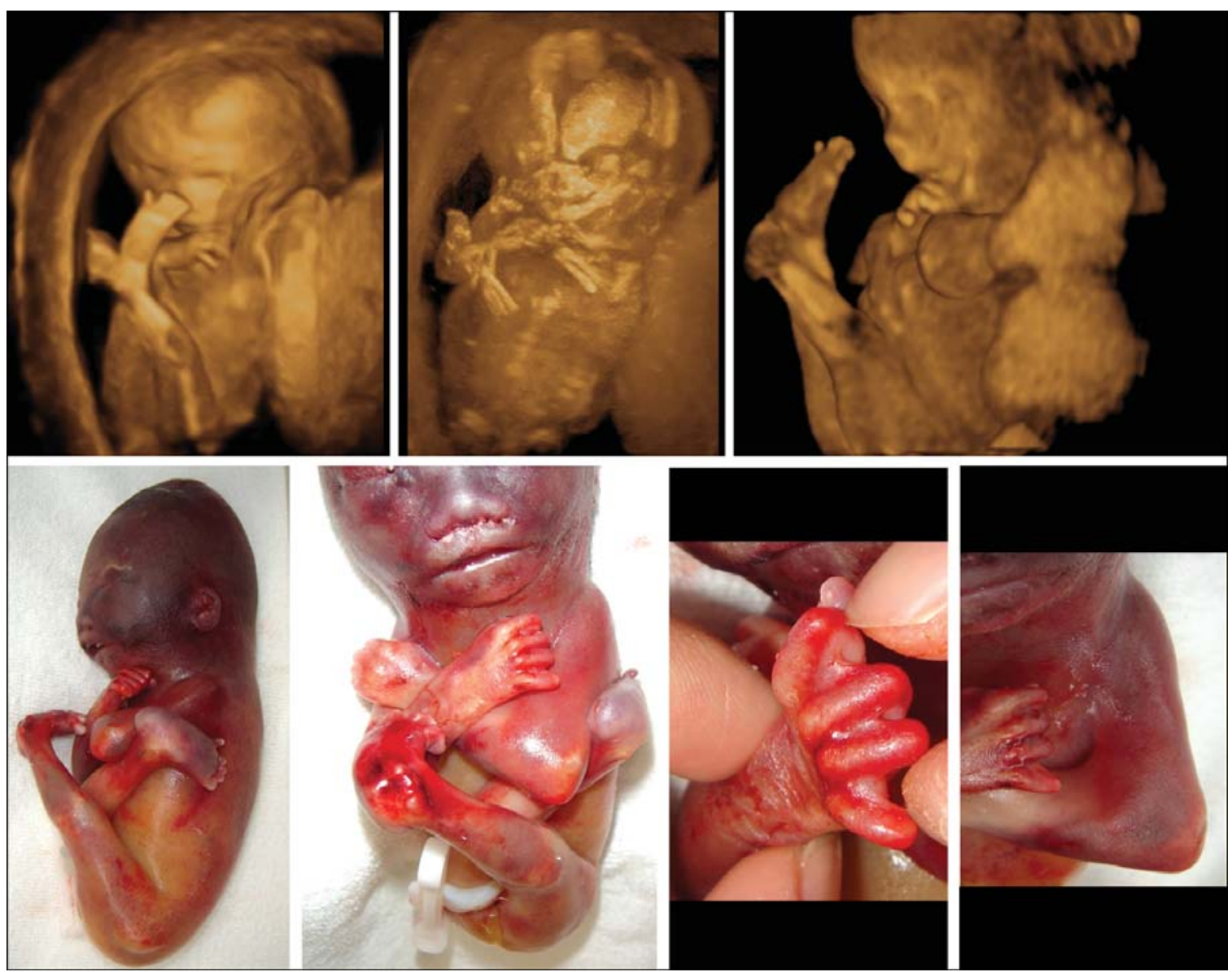

Fig. 35: Lethal pterygium syndrome detected at 14 weeks. (upper) 3D reconstructed images. Middle image demonstrated the bony structure by maximum mode. The fetus did not move with the same appearance for weeks. (lower) Aborted fetus at 20 weeks. The same appearance as prenatal images is seen. The wing-like shoulders and elbows, finger webs are characteristics of this syndrome 


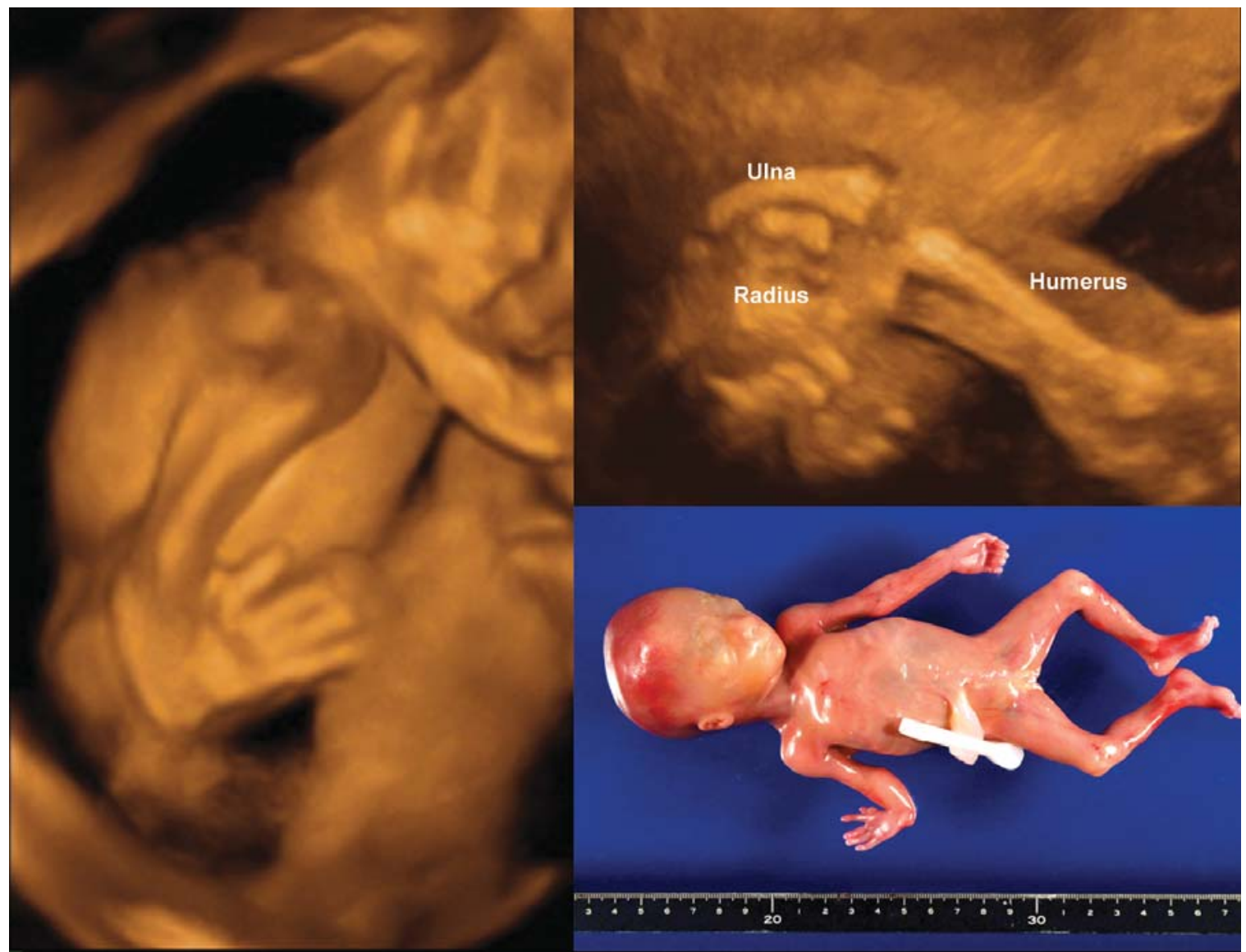

Fig. 36: Right arm abnormality at 18 weeks. (left) Abnormal appearance of right arm by 3D reconstructed image. Short forearm and thumb abnormality are demonstrated. (upper right) Maximum mode image of the right arm. Short ulna and extremely short radius are clearly demonstrated. (lower right) Postmortem appearance of the aborted fetus. (Cortesy of Dr H Takemura, Kosaka Women's Hospital, Higashiosaka, Japan. Partial chromosomal abnormality was confirmed)

with no other abnormalities in a case of partial chromosomal abnormality. Figure 37 demonstrates two cases of thanatophoric dysplasia at 19-20 weeks.

Limb abnormalities can occur as isolated findings or as one component of a syndrome or sequence. However, only $5 \%$ of congenital hand anomalies occur as part of a recognized syndrome. ${ }^{38}$ Figure 34 shows thin limbs with no other abnormalities in a case of triploidy. Figure 35 demonstrates 3D ultrasound images and postmortem pictures in a case of lethal pterygium syndrome. Pterygium is used to describe webbing of the skin across the joint. The term means "wing-like”. Limb pterygia at birth indicates an abnormal developmental process probably occurring in the first trimester and involving reduced mobility of the webbed limb. Prenatal diagnosis in the first trimester was reported. ${ }^{39}$ Figure 36 shows unilateral forearm and thumb abnormality with no other abnormalities in a case of partial chromosomal abnormality. Figure 37 demonstrates two cases of thanatophoric dysplasia at 19-20 weeks.
Recent high resolutional ultrasound can demonstrate finger/ toe abnormality in detail. Polydactyly (Figures 38 and 39), syndactyly (Figs 40 and 41) and cleft hand/toe (Figs 42 to 44) are clearly seen by 3D ultrasound during pregnancy. Thumb abnormality, especially adducted thumb is one of the important signs for assessment of fetal brain development. ${ }^{40,41}$ Genetic hydrocephalus or brain abnormalities which is strongly related to L1CAM gene, are associated with adducted thumbs. ${ }^{42,43}$ as shown in Figure 45.

\section{CONCLUSION}

This article reviews and illustrates the power of highresolution 3D ultrasound in the definition of normal fetal anatomy as well as in the identification of congenital anomalies. The advances of 3D ultrasound in the last decade is remarkable and has contributed to the field of embryology, fetal physiology and pathology. Further researches by 3D 


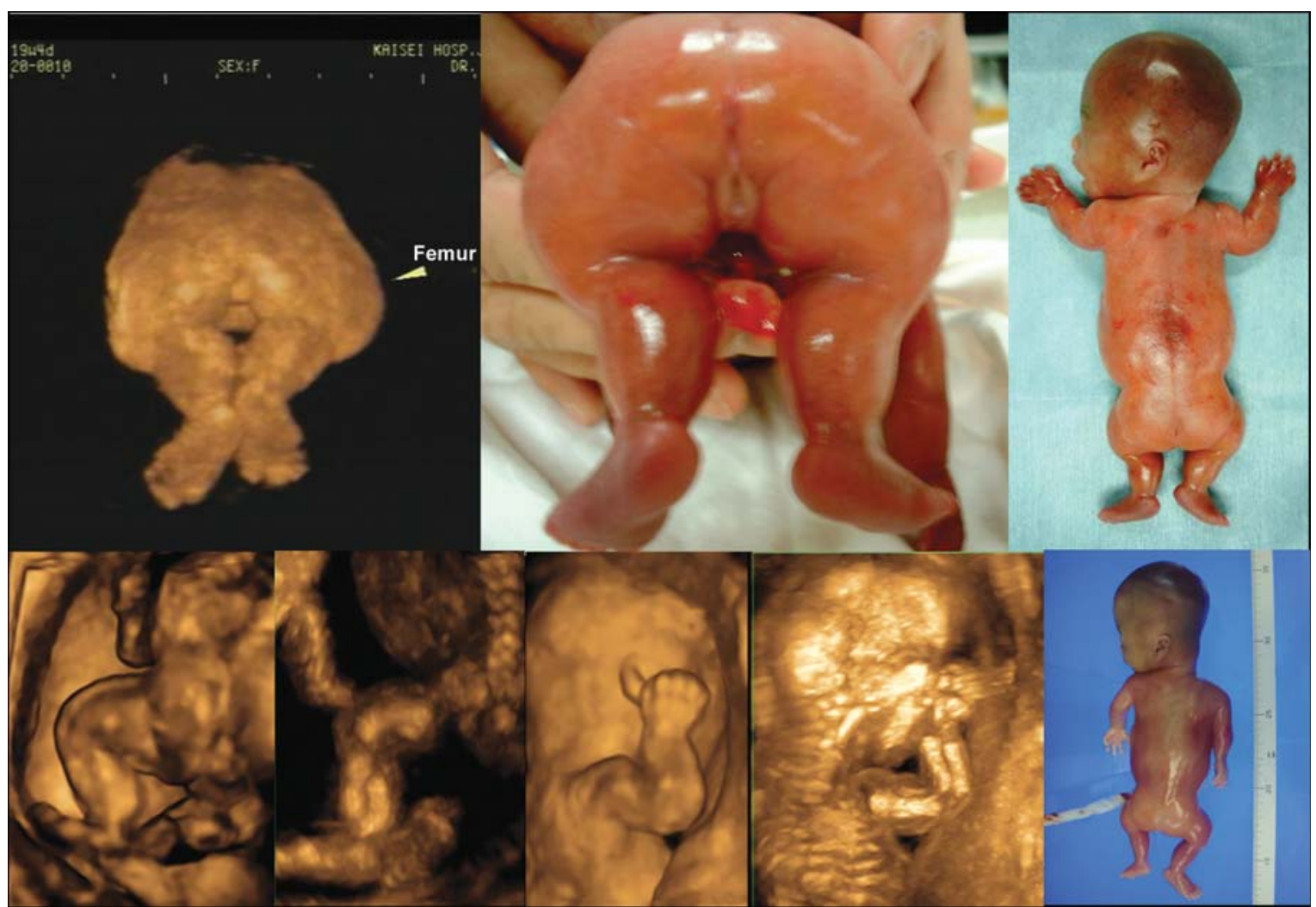

Fig. 37: Thanatophoric dysplasia at 19 weeks. 3D reconstructed images and postmortem appearance of two cases (upper and lower cases) with short limbs and abnormally curved femurs, are shown

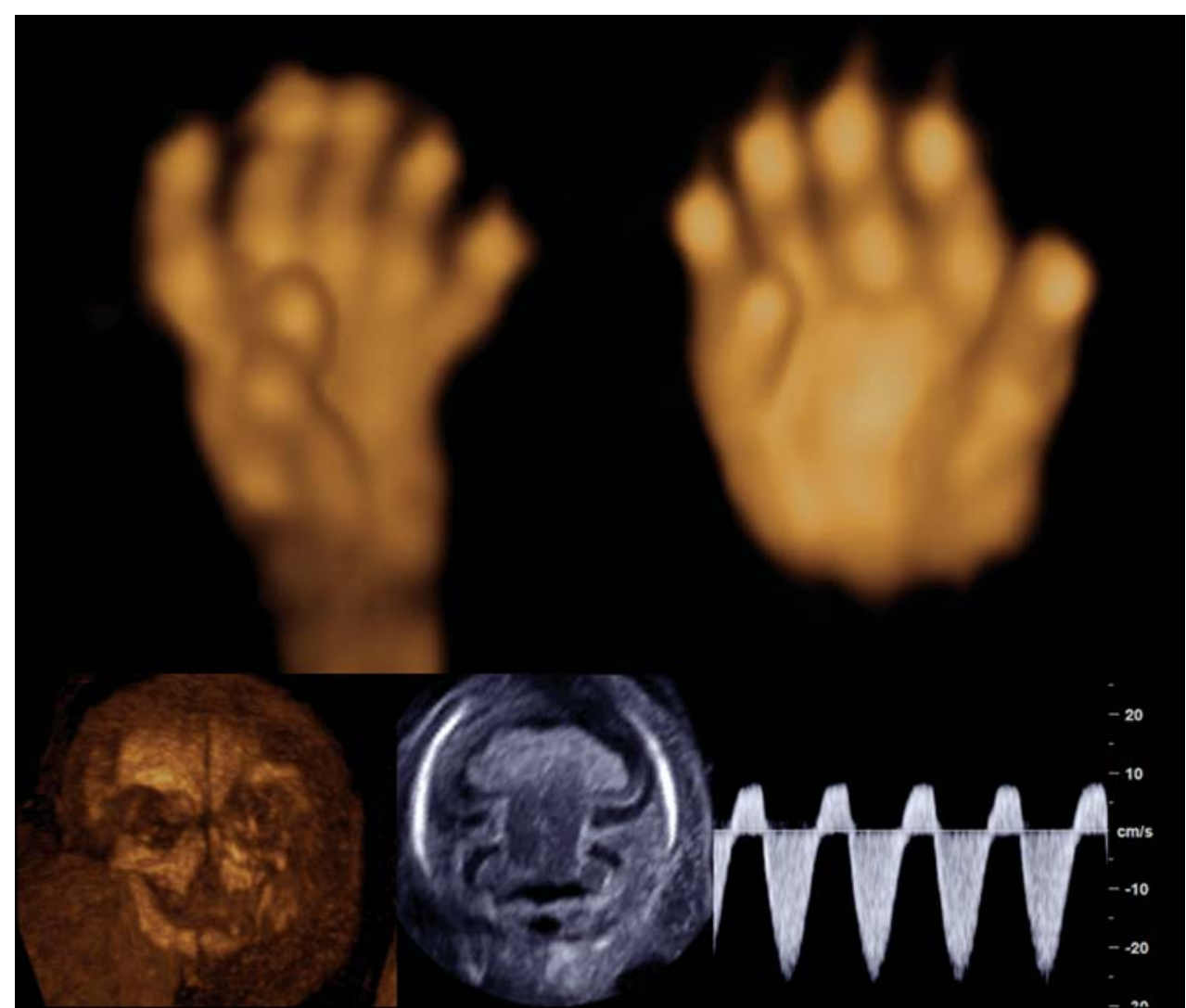

Fig. 38: Polydactyly at 14 weeks. Bilateral polydactyly is clearly demonstrated in upper figures. This case has cleft palate (lower left), holoprosencephaly (lower middle) and umbilical artery reversed flow 


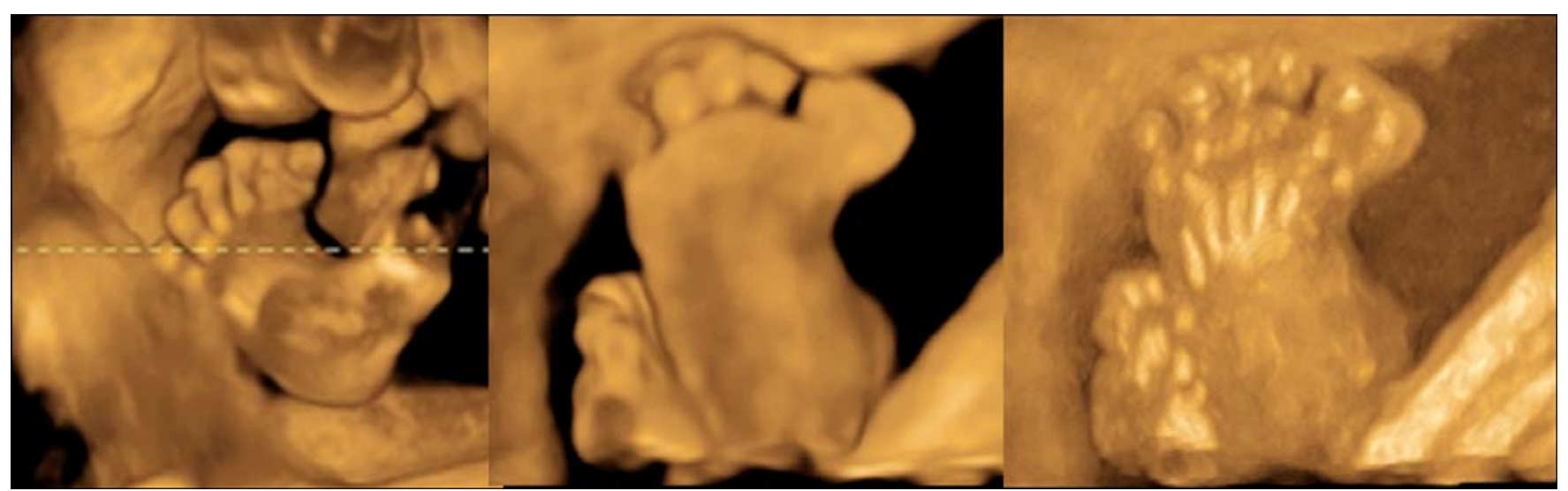

Fig. 39: Polydactyly/syndactyly at 19 weeks. 3D reconstructed images of the right toe. The first big toe is demonstrated in the left and middle figures. The right Figure clearly shows 6 toe bones
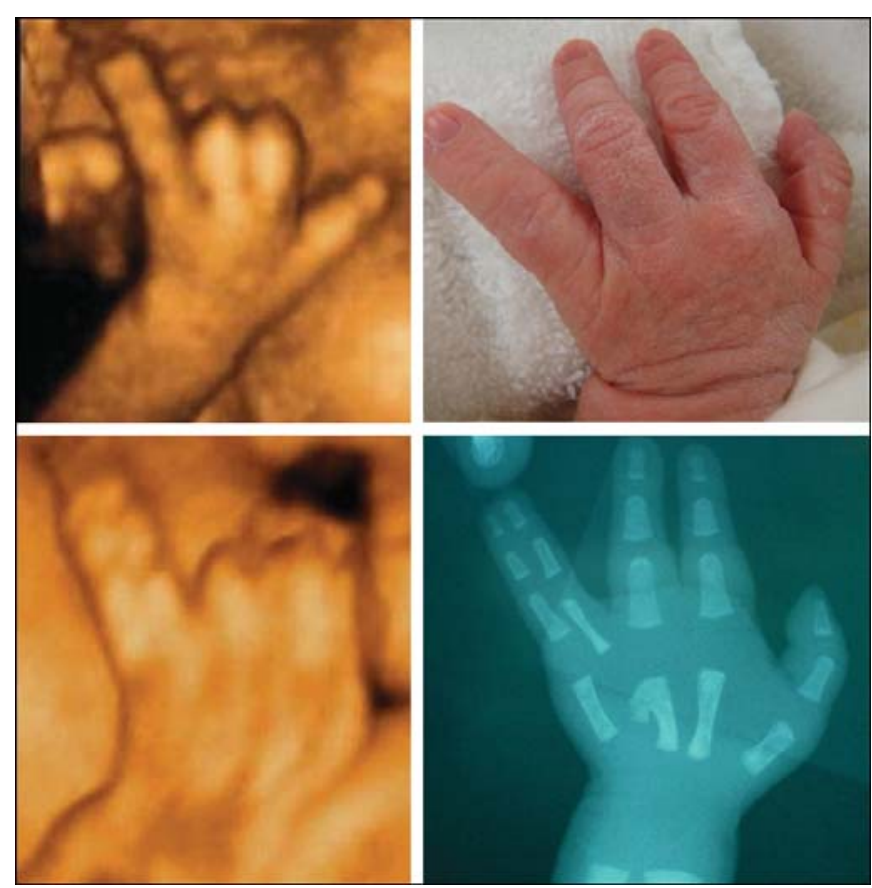

Fig. 40: Syndactyly (single finding) at 28 weeks. (left) 3D reconstructed images of the left hand. The forth and fifth fingers are almost the same size and abnormally stretched together. (upper right) Postnatal hand appearance. (lower right) Postnatal X-ray image
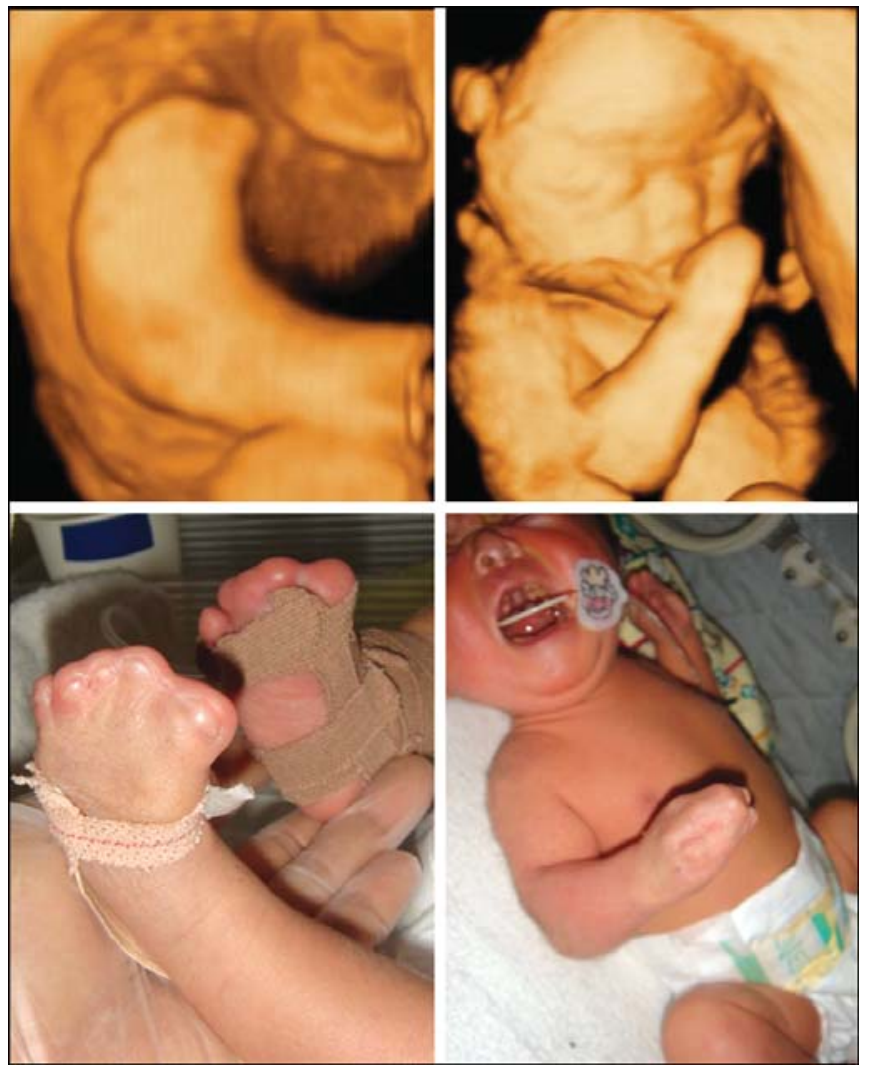

Fig. 41: Syndactyly in a case of Apert syndrome at 31 weeks. (upper) 3D reconstructed images of the foot and hand. All of toes and fingers are sticked together. (lower) Postnatal appearance of foot and hand. The same appearance as prenatal imaging is seen 

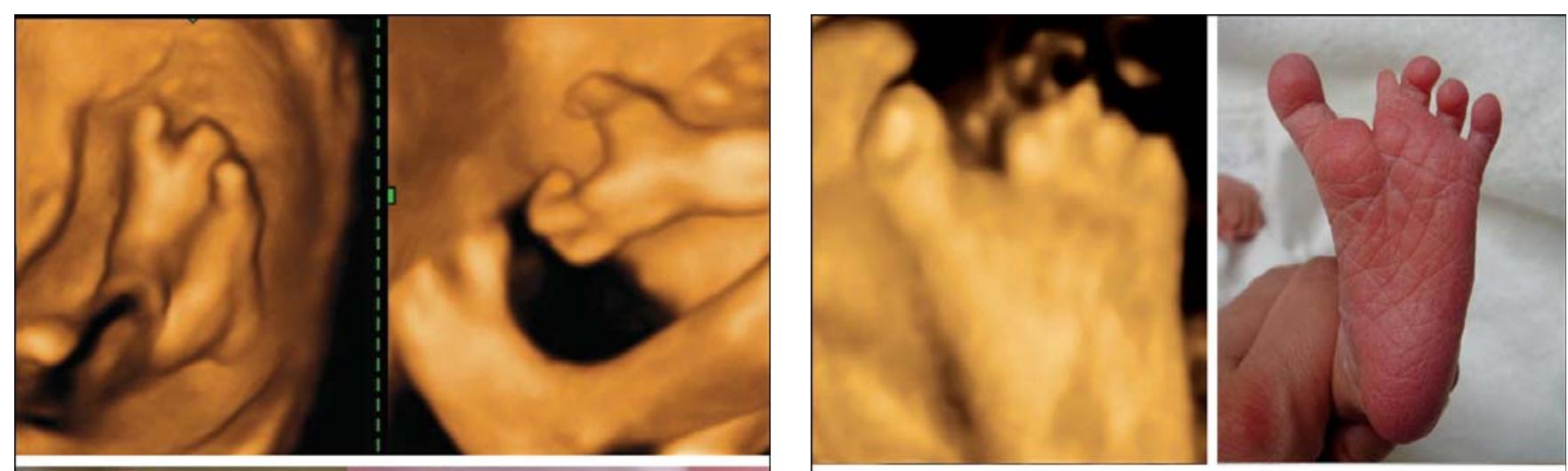

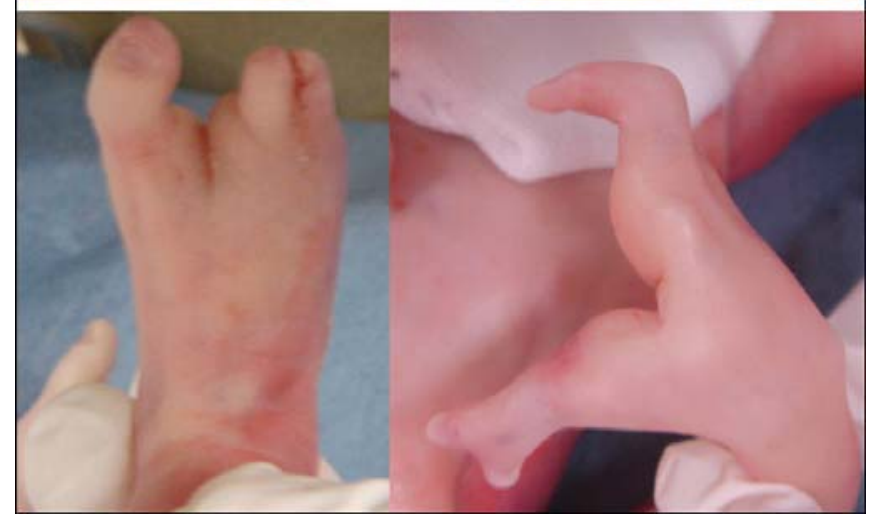

Fig. 42: Cleft foot and cleft hand, Oligodactyly/syndactyly at 28 weeks. (upper) 3D reconstructed images of the foot and hand. (lower) Postnatal appearance

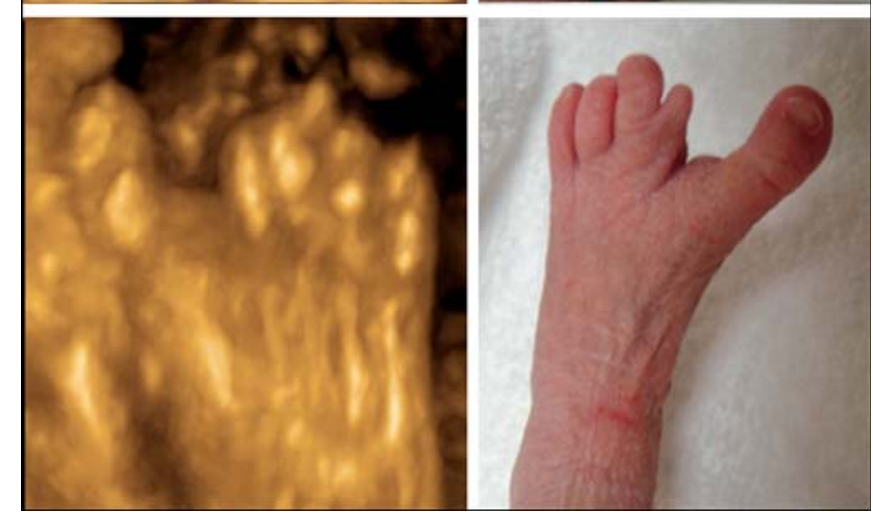

Fig. 43: Cleft foot with toe dysplasia at 35 weeks. (upper left) 3D reconstructed image. (lower left) Maximum mode. (right) Postnatal appearance

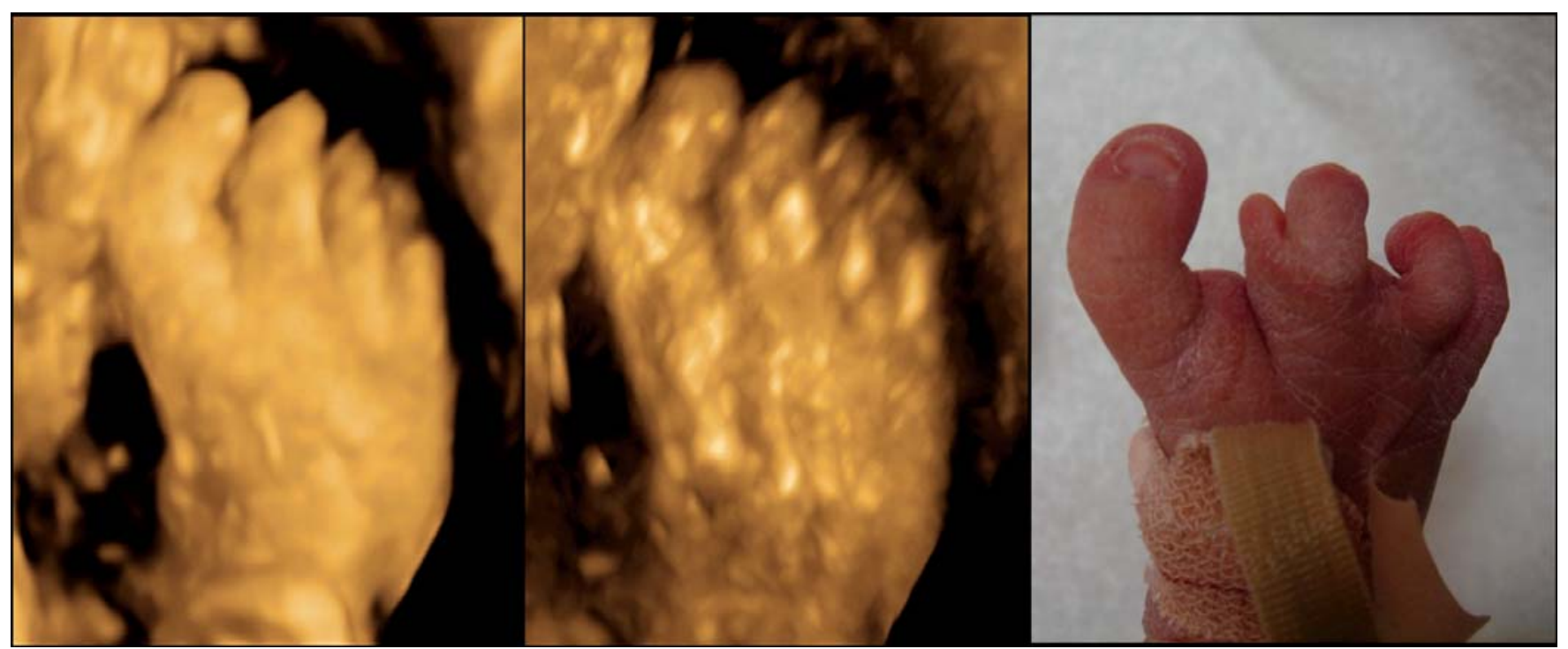

Fig. 44: Cleft foot with toe dysplasia and first toe contracture at 35 weeks (same case as Fig. 43). (left) 3D reconstructed image. (middle) Maximum mode. (right) Postnatal appearance 


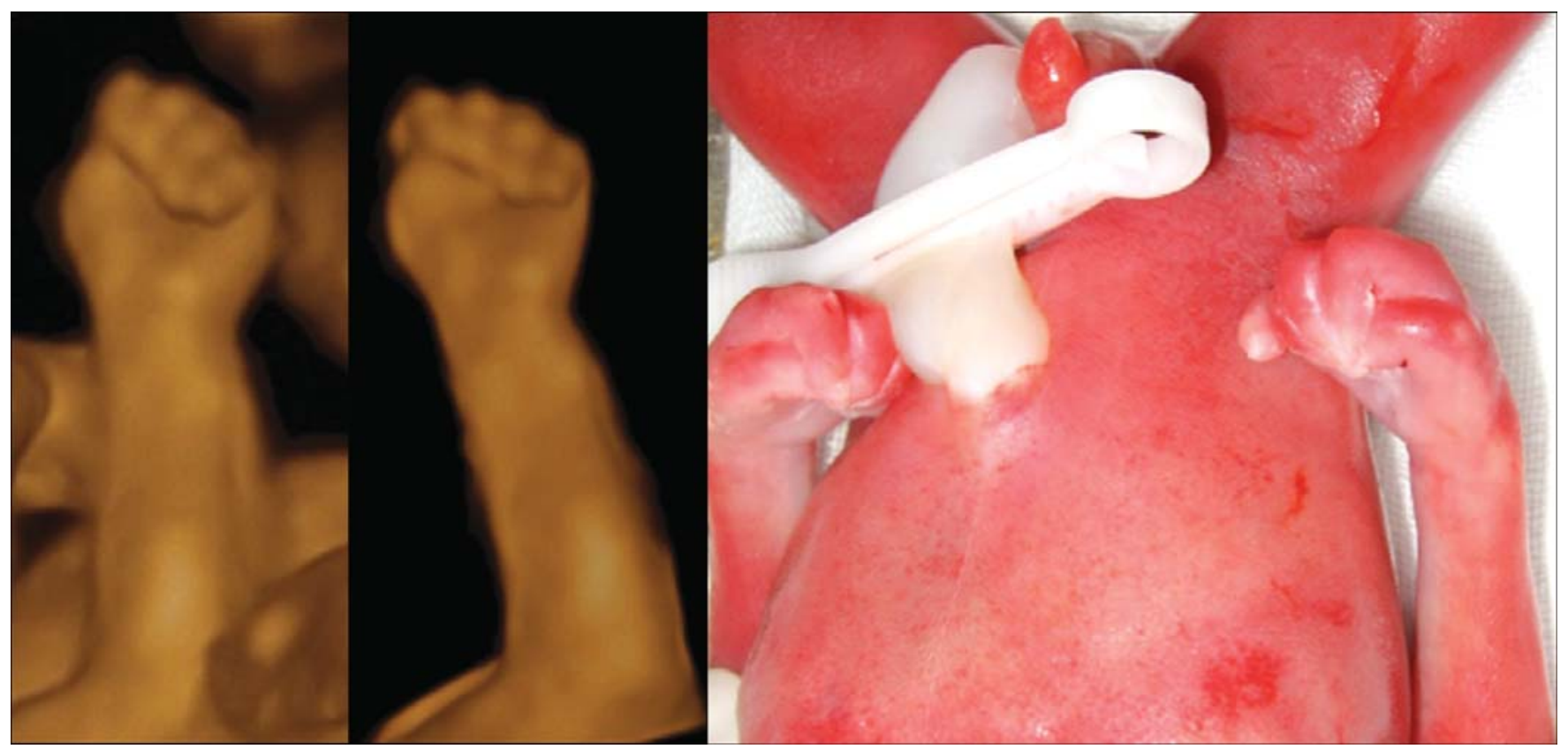

Fig. 45: Adducted thumbs in a case of genetic hydrocephalus: (left and middle) 3D reconstructed images of adducted thumb. (right) Postmortem appearance of clenched hands with adducted thumbs. This case is complicated with hydrocephalus, partial agenesis of the corpus callosum. Postmortem genetic test revealed L1CAM disorder

ultrasound will bring more accurate and detailed prenatal diagnosis for better prenatal care.

\section{ACKNOWLEDGMENTS}

The authors thank members of Global Ultrasound and Information Technologies and Women's Health care and Specialty of General Electrics Health care (Milwaukee, USA) for their technical support and collaboration in sonoembryology, sonoanatomy and neurosonology.

\section{REFERENCES}

1. Timor-Tritsch IE, Peisner DB, Raju S. Sonoembryology: An organ-oriented approach using a high-frequency vaginal probe. J Clin Ultrasound 1990;18(4):286-98.

2. Benoit B, Hafner T, Kurjak A, Kupesic S, Bekavac I, et al. Three-dimensional sonoembryology. J Perinat Med 2002;30(1):63-73.

3. Kurjak A, Pooh RK, Merce LT, Carrera JM, Salihagic-Kadic A, et al. Structural and functional early human development assessed by three-dimensional and four-dimensional sonography. Fertil Steril 2005;84(5):1285-99.

4. Kurjak A, Zudenigo D, Predanic M, Kupesic S. Recent advances in the Doppler study of early fetomaternal circulation. J Perinat Med 1993;21:419-39.

5. Kurjak A, Schulman H, Predanic A, Predanic M, Kupesic S, et al. Fetal choroid plexus vascularization assessed by color flow ultrasonography. J Ultrasound Med 1994;13:841-44.

6. Pooh RK, Aono T. Transvaginal power Doppler angiography of the fetal brain. Ultrasound Obstet Gynecol 1996;8:417-21.
7. Nicolaides KH. Nuchal translucency and other first-trimester sonographic markers of chromosomal abnormalities. Am J Obstet Gynecol 2004;191:45-67.

8. Cicero S, Curcio P, Papageorghiou A, Sonek J, Nicolaides K. Absence of nasal bone in fetuses with trisomy 21 at 11-14 weeks of gestation: Kn observational study. Lancet 2001;358:1665-67.

9. Zoppi MA, Ibba RM, Axiana C, Floris M, Manca F, Monni G. Absence of fetal nasal bone and aneuploidies at first-trimester nuchal translucency screening in unselected pregnancies. Prenat Diagn 2003;23:496-500.

10. Cicero S, Rembouskos G, Vandecruys H, Hogg M, Nicolaides $\mathrm{KH}$. Likelihood ratio for trisomy 21 in fetuses with absent nasal bone at the 11-14-week scan. Ultrasound Obstet Gynecol 2004;23:218-23.

11. Cicero S, Avgidou K, Rembouskos G, Kagan KO, Nicolaides $\mathrm{KH}$. Nasal bone in first-trimester screening for trisomy 21. Am J Obstet Gynecol 2006;195:109-14.

12. Rembouskos G, Cicero S, Longo D, Vandecruys H, Nicolaides $\mathrm{KH}$. Assessment of the fetal nasal bone at 11-14 weeks of gestation by three-dimensional ultrasound. Ultrasound Obstet Gynecol 2004;23:232-36.

13. Benoit B, Chaoui R. Three-dimensional ultrasound with maximal mode rendering: A novel technique for the diagnosis of bilateral or unilateral absence or hypoplasia of nasal bones in secondtrimester screening for Down syndrome. Ultrasound Obstet Gynecol 2005;25:19-24.

14. Cicero S, Curcio P, Rembouskos G, Sonek J, Nicolaides KH. Maxillary length at 11-14 weeks of gestation in fetuses with trisomy 21. Ultrasound Obstet Gynecol 2004;24:19-22.

15. Teoh M, Meagher S. First-trimester diagnosis of micrognathia as a presentation of Pierre Robin syndrome. Ultrasound Obstet Gynecol 2003;21:616-18. 
16. Tsai MY, Lan KC Ou CY, Chen JH, Chang SY, Hsu TY. Assessment of the facial features and chin development of fetuses with use of serial three-dimensional sonography and the mandibular size monogram in a Chinese population. Am J Obstet Gynecol 2004;190:541-46.

17. Pooh RK. Three-dimensional ultrasound of the fetal brain. In Kurjak A ed. Clinical application of 3D ultrasonography. Parthenon Publishing, Carnforth 2000;176-80.

18. Pooh RK, Pooh KH, Nakagawa Y, Nishida S, Ohno Y. Clinical Application of Three-dimensional Ultrasound in Fetal Brain Assessment. Croat Med J 2000;41:245-51.

19. Blaas HG, Eik-Nes SH, Kiserud T, Berg S, Angelsen B, Olstad B. Three-dimensional imaging of the brain cavities in human embryos. Ultrasound Obstet Gynecol 1995;5:228-32.

20. Blaas HG, Eik-Nes SH, Berg S, Torp H. In-vivo threedimensional ultrasound reconstructions of embryos and early fetuses. Lancet 1998;352:1182-86.

21. Timor-Tritsch IE, Monteagudo A, Mayberry P. Threedimensional ultrasound evaluation of the fetal brain: the three horn view. Ultrasound Obstet Gynecol. 2000;16:302-06.

22. Monteagudo A, Timor-Tritsch IE, Mayberry P. Threedimensional transvaginal neurosonography of the fetal brain: 'Navigating' in the volume scan.Ultrasound Obstet Gynecol 2000;16:307-13.

23. Pooh RK, Nagao Y, Pooh KH. Fetal neuroimaging by transvaginal 3D ultrasound and MRI. Ultrasound Rev Obstet Gynecol 2006;6:123-34.

24. Pooh RK, Pooh KH. Fetal neuroimaging with new technology. Ultrasound Review Obstet Gynecol 2002;2:178-81.

25. Pooh RK. Fetal Brain Assessment by Three-Dimensional Ultrasound. In Kurjak A, Kupesic S eds. Clinical Application of 3D Sonography.Carnforth,UK: Parthenon Publishing 2000;17179.

26. Pooh RK, Pooh KH. Transvaginal 3D and Doppler ultrasonography of the fetal brain. Semin Perinatol 2001;25:38-43.

27. Pooh RK, Pooh KH. The assessment of fetal brain morphology and circulation by transvaginal 3D sonography and power Doppler. J Perinat Med 2002;30:48-56.

28. Pooh RK, Pooh KH. Fetal Ventriculomegaly. Donald school J Ultrasound Obstet Gynecol 2007;2(2):40-46.

29. Pooh RK, Maeda K, Pooh KH. An Atlas of Fetal Central Nervous System Disease. Diagnosis and Management. Parthenon CRC Press, London, New York, 2003.
30. Pooh RK. Neuroscan of Congenital Brain Abnormality. Fetal Neurology by Pooh RK, Kurjak A, Jaypee Brothers Medical Publishers, New Delhi, 2009;59-139.

31. Pooh RK. Fetal Neuroimaging of Neural Migration Disorder. Ultrasound Clinics, Elsevier 2008;3(4):541-52.

32. Blaas HG, Eik-Nes SH, Isaksen CV. The detection of spina bifida before 10 gestational weeks using two- and threedimensional ultrasound. Ultrasound Obstet Gynecol 2000;16(1):25-29.

33. Scott RM, Wolpert SM, Bartoshesky LE, Zimbler S, Karlin L.Segmental spinal dysgenesis. Neurosurgery Apr 1988;22(4):739-44.

34. Doyle NM, Lally KP. The CDH Study Group and advances in the clinical care of the patient with congenital diaphragmatic hernia. Semin Perinatol Jun 2004;28(3):174-84.

35. Daskalakis G, Anastasakis E, Souka A, Manoli A, Koumpis C, et al. First trimester ultrasound diagnosis of congenital diaphragmatic hernia. J Obstet Gynaecol Res 2007;33:870-72.

36. Sanz-Cortés M, Raga F, Bonilla-Musoles F. Prenatal diagnosis of congenital cystic adenomatoid malformation using threedimensional inversion rendering: A case report. J Obstet Gynaecol Res Aug 2008;34(4 Pt 2):631-34.

37. Siqueira Rabelo EA, Oliveira EA, Silva JM, Oliveira DS, Colosimo EA. Ultrasound progression of prenatally detected multicystic dysplastic kidney. Urology Nov 2006;68(5):1098-102.

38. Bolitho DG. Hand, Congenital hand deformities. emedicine 2006. http://www.emedicine.com/plastic/TOPIC298.HTM.

39. Gundogan M, Fong K, Keating S, Pierre-Louis J, Chitayat D. First trimester ultrasound diagnosis of lethal multiple pterygium syndrome. Fetal Diagn Ther 2006;21(5):466-70.

40. Kurjak A, Miskovic B, Stanojevic M, Amiel-Tison C, Ahmed $B$, et al. New scoring system for fetal neurobehavior assessed by three- and four-dimensional sonography. J Perinat Med 2008;36(1):73-81.

41. Kurjak A, Tikvica A, Stanojevic M, Miskovic B, Ahmed B, et al. The assessment of fetal neurobehavior by three-dimensional and four-dimensional ultrasound. J Matern Fetal Neonatal Med 2008;21(10):675-84.

42. Yamasaki M, Thompson P, Lemmon V. CRASH syndrome: Mutations in L1CAM correlate with severity of the disease. Neuropediatrics Jun 1997;28(3):175-78.

43. Kanemura Y, Takuma Y, Kamiguchi H, Yamasaki M. First case of L1CAM gene mutation identified in MASA syndrome in Asia. Congenit Anom (Kyoto) Jun 2005;45(2):67-69. 